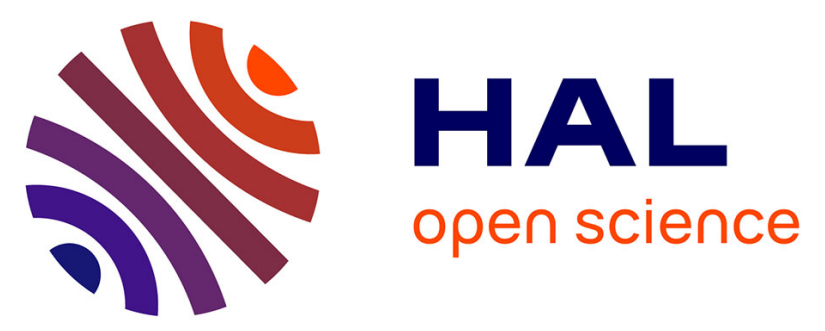

\title{
Cooperative Heterodimer Formation Between Per-Guadinylated and Carboxylated or Phosporylated Cyclodextrins in DMSO and DMSO-Water Studied by NMR Spectroscopy and Microcalorimetry
}

Konstantina Yannakopoulou, George Nounesis, Angelos Thanassoulas, Katerina Fotiadou

\section{To cite this version:}

Konstantina Yannakopoulou, George Nounesis, Angelos Thanassoulas, Katerina Fotiadou. Cooperative Heterodimer Formation Between Per-Guadinylated and Carboxylated or Phosporylated Cyclodextrins in DMSO and DMSO-Water Studied by NMR Spectroscopy and Microcalorimetry. Supramolecular Chemistry, 2011, pp.1. 10.1080/10610278.2010.550918 . hal-00687803

\section{HAL Id: hal-00687803 https://hal.science/hal-00687803}

Submitted on 15 Apr 2012

HAL is a multi-disciplinary open access archive for the deposit and dissemination of scientific research documents, whether they are published or not. The documents may come from teaching and research institutions in France or abroad, or from public or private research centers.
L'archive ouverte pluridisciplinaire HAL, est destinée au dépôt et à la diffusion de documents scientifiques de niveau recherche, publiés ou non, émanant des établissements d'enseignement et de recherche français ou étrangers, des laboratoires publics ou privés. 


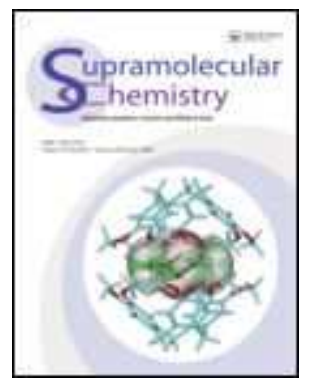

\section{Cooperative Heterodimer Formation Between Per- Guadinylated and Carboxylated or Phosporylated Cyclodextrins in DMSO and DMSO-Water Studied by NMR Spectroscopy and Microcalorimetry}

\begin{tabular}{|r|l|}
\hline Journal: & Supramolecular Chemistry \\
\hline Manuscript ID: & GSCH-2010-0203.R1 \\
\hline Manuscript Type: & Full Paper \\
\hline Author: & 18 -Nov-2010 \\
\hline Complete List of Authors: & $\begin{array}{l}\text { Yannakopoulou, Konstantina; NCSR "Demokritos", Physical } \\
\text { Chemistry } \\
\text { Nounesis, George; NCSR "Demokritos", Radioisotopes and } \\
\text { Radiodiagnostic Products } \\
\text { Thanassoulas, Angelos; NCSR "Demokritos", Radioisotopes and } \\
\text { Radiodiagnostic Products } \\
\text { Fotiadou, Katerina; NCSR "Demokritos", Physical Chemistry }\end{array}$ \\
\hline \hline Keywords: & $\begin{array}{l}\text { guanidinylated, cyclodextrin, heterodimer, carboxylated, } \\
\text { cooperativity }\end{array}$ \\
\hline $\begin{array}{l}\text { Note: The following files were submitted by the author for peer review, but cannot be converted } \\
\text { to PDF. You must view these files (e.g. movies) online. }\end{array}$ \\
\hline \begin{tabular}{l} 
Scheme 2.cdx \\
\hline
\end{tabular}
\end{tabular}

\section{SCHOLARONE ${ }^{\text {M }}$ Manuscripts}




\section{Cooperative Heterodimer Formation Between Per-Guadinylated and Carboxylated or Phosphorylated Cyclodextrins in DMSO and DMSO- Water Studied by NMR Spectroscopy and Microcalorimetry}

Katerina Fotiadou, ${ }^{\mathrm{a}}$ Angelos Thanassoulas, ${ }^{\mathrm{b}}$ George Nounesis, ${ }^{\mathrm{b}}$ Konstantina Yannakopoulou $^{\mathrm{a} *}$

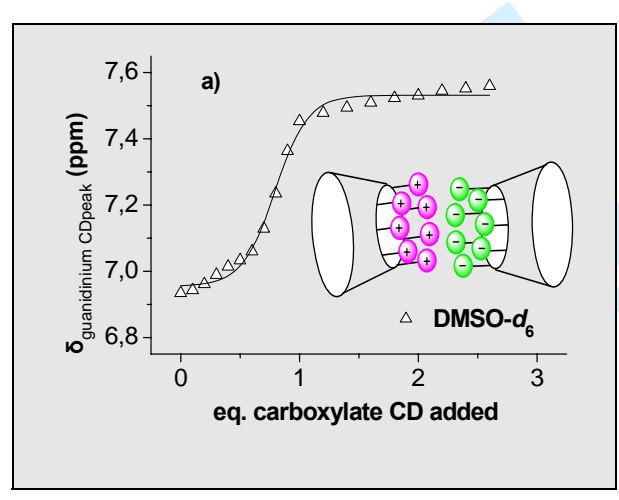

Anionic cyclodextrins (CDs) as triethylammonium salts interact with the picrate salt of a positively charged $\mathrm{CD}$ to form stable heterodimers in solution. The association constants, $K_{\mathrm{a}}$, in DMSO$d_{6}$ and in DMSO- $d_{6} / \mathrm{H}_{2} \mathrm{O}(80 / 20, \mathrm{v} / \mathrm{v})$ range from $\sim 10^{5} \mathrm{M}^{-1}$ to $\sim 10^{4} \mathrm{M}^{-1}$. Heterodimer formation is more favored in DMSO than in $\mathrm{DMSO} / \mathrm{H}_{2} \mathrm{O}(80 / 20 \mathrm{v} / \mathrm{v})$. Multivalency in the interactions is manifested by positive cooperativity, negative enthalpy of formation $(\Delta \mathrm{H})$, and sizeable negative entropy $(\Delta S)$, in support of development of well ordered supramolecular structures in solution. 


\section{Cooperative Heterodimer Formation between Per-Guadinylated and Carboxylated or Phosphorylated Cyclodextrins in DMSO and DMSO-Water Studied by NMR Spectroscopy and Microcalorimetry}

Katerina Fotiadou, ${ }^{\mathrm{a}}$ Angelos Thanassoulas, ${ }^{\mathrm{b}}$ George Nounesis, ${ }^{\mathrm{b}}$ Konstantina Yannakopoulou ${ }^{\mathrm{a} *}$

${ }^{a}$ Institute of Physical Chemistry, ${ }^{b}$ Institute of Radioisotopes and Radiodiagnostic Products, National Centre for Scientific Research “Demokritos”, 15310 Aghia Paraskevi, Greece.

*Corresponding author. E-mail: dyanna@chem.demokritos.gr 


\begin{abstract}
The anionic cyclodextrins (CDs), heptakis[6-(3-thiopropionate)-6-deoxy]- $\beta$-CD, heptakis[(6(thioethanoate)-6-deoxy]- $\beta$-CD and partially phosphorylated 6-(aminoethylphosphate)-6-deoxy-

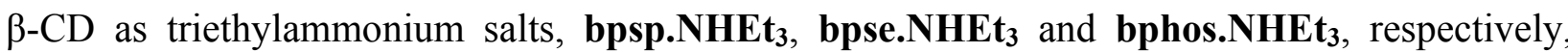
interacted with the positively charged picrate salt of heptakis[6-(guanidino)-6-deoxy]- $\beta-C D$, bguan.picrate, to form heterodimers as shown by NMR spectroscopic and microcalorimetric (ITC) titrations in solution. Association constants, $K_{\mathrm{a}}\left(\mathrm{M}^{-1}\right)$ in DMSO- $d_{6}$ and in DMSO- $d_{6} / \mathrm{H}_{2} \mathrm{O}$ $(80 / 20, \quad \mathrm{~V} / \mathrm{v}) \quad$ were: $\quad$ bguan.picrate/bpsp. NHEt $_{3}, \quad 6.4 \times 10^{5}$ and $5.9 \times 10^{4}$; bguan.picrate/bpse. NHEt $_{3}, \quad 4.2 \times 10^{4}$ and $1.2 \times 10^{4}$; the approximate values for bguan.pierate/bphos.NHE $t_{3}$-(partially phosphorylated), $(0.34 \pm 0.15) \cdot 10^{4}$-are also indicative of heterodimer formation.ITC data in DMSO agreed with those above: bguan.picrate/bpsp.NHEt ${ }_{3}$, $K_{\mathrm{a}}=4.7 \pm 0.032 \times 10^{5} \quad \mathrm{M}^{-1}, \quad \Delta \mathrm{H}=-83.97 \quad \mathrm{~kJ} \cdot \mathrm{mol}^{-1}, \quad \Delta \mathrm{S}=-173.19 \quad \mathrm{~J} . \mathrm{mol}^{-1} \cdot \mathrm{K}^{-1} ; \quad$ bguan.picra-

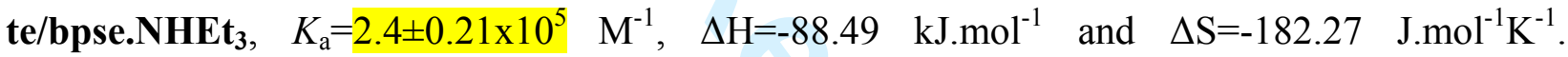
Heterodimers are highly stable in DMSO and less in $\mathrm{DMSO} / \mathrm{H}_{2} \mathrm{O}$. Multivalency in the interactions is manifested by positive cooperativity, negative enthalpy of formation $(\Delta \mathrm{H})$, and sizeable negative entropy $(\Delta S)$, in support of development of well ordered supramolecular structures in solution.
\end{abstract}

Keywords: heterodimer, guadinylated, carboxylated, cyclodextrin, cooperativity 


\section{Introduction}

Non-covalent interactions that lay at the heart of molecular recognition processes in systems either biological or synthetically designed cover a wide range of energies. Coulombic and dipole-dipole non-covalent interactions can be either attractive or repulsive depending on the sign of charges and the mutual disposition of dipoles (1), however all forces are distance dependent. Ion-pair binding, complemented with other non-covalent associations can very effectively stabilise the interacting molecules, whereas the solvent plays a key role in the overall stabilisation. By selecting the geometry and functionalities present to components, artificial selfassembling species with cavities can be formed by the reversible noncovalent interaction of two or more subunits. The new entities will posses a well-defined structure in solution and be capable of binding other molecules. Thus a vast array of functional supramolecular architectures (capsules, tweezers, clips, e.t.c) has be created $(1,2,3,4,5,6)$.

The guanidinium group, present in proteins as the end group of the amino acid arginine but also in many artificial recognition systems $(1,7,8)$ has both anion binding and hydrogen bond donating properties and plays a key role in ionic recognition and association. The guanidinium group is protonated at neutral $\mathrm{pH}\left(\mathrm{p} K_{\mathrm{a}}\right.$ of guanidine, 13.5; $\mathrm{p} K_{\mathrm{a}}$ of arginine, 12.5) and due to its flat, Y-shaped geometry forms strong electrostatic and directed H-bonds with carboxylate and phosphate groups (1). If many guanidinium groups are present on a core molecule, the multivalency of interactions is expected to strongly enhance the binding to multianionic substrates $(9)$.

Cyclodextrins (CDs) are water soluble cyclic oligosaccharides that have the shape of a cup and form inclusion complexes with organic molecules (8) that enter their hydrophobic cavity. The presence of guanidino groups on the primary (narrow) side of CDs (Scheme 1a), i.e. in hexakis-, heptakis- and octakis(6-guanidino-6-deoxy)-CDs (10), endows them with unique properties: (i) they include anionic guests strongly and preferentially in their cavity (10), consequently they can efficiently capture nucleotides (11), (iii) they strongly bind DNA which in 
their presence is packed into nanoparticles (10). The ability to include nucleotides has been previously demonstrated with amino-substituted CDs (12-16) as well as mono-or bis-guanidinoCDs $(15,17)$ the latter presenting an enthalpic advantage over the amino CDs in stabilization of binding.

The question of whether per-guanidino CDs would form stable supramolecular heterodimers with anionic and specifically per-carboxylate-substituted CDs (Scheme 1b, bpse and bpsp) and phosphate-substituted CDs (Scheme 1c, bphos) has led to the present study based on results from NMR spectroscopy and isothermal titration calorimetry (ITC).

$<$ Scheme $1>$

Specifically, the question of stabilization via multivalency is addressed as well as its correlation with the structural features of the interacting CDs. The solvents of choice were the polar aprotic dimethyl sulphoxide (DMSO, $\varepsilon=47.2)$ and the mixture DMSO/ $\mathrm{H}_{2} \mathrm{O}(80 / 20$, v/v. Water was avoided since its large dielectric constant, $\varepsilon=80$ (18) is expected to decrease the strength of association between ions, the coulombic attraction being proportional to the interacting charges but inversely proportional to $\varepsilon$, and also competes for hydrogen bonding with the interacting host-guest system. Further, in DMSO- $d_{6}$ and DMSO- $d_{6} /$ water (but not in $\mathrm{D}_{2} \mathrm{O}$ or $\left.\mathrm{H}_{2} \mathrm{O} / 10 \% \mathrm{D}_{2} \mathrm{O}\right)$ the chemical shifts changes of the exchangeable protons of the guanidinium groups could be monitored during titration runs by ${ }^{1} \mathrm{H}$ NMR spectroscopy and thus their interactions with the carboxyl groups would be directly measured.

\section{Results and Discussion}

\section{Preparation of charged cyclodextrins.}

Negatively charged CDs, heptakis[6-(3-thiopropionate)-6-deoxy]- $\beta$-CD (bpsp) and heptakis[(6(2-thioethanoate)-6-deoxy]- $\beta$-CD (bpse) (Scheme 1b) were prepared as their sodium salts, according to the literature (19). They were then converted to the corresponding water insoluble 
acids and subsequently to triethylammonium salts, bpsp.NHEt ${ }_{3}$, bpse.NHEt , $_{3}$, respectively, in situ (Supplementary Figures S1, S2). These triethylammonium salts were water and DMSO soluble. The positively charged cyclodextrin, heptakis(6-guanidino-6-deoxy)- $\beta$-cyclodextrin hydrochloride (bguan.HCI) (10) was the selected interacting partner. Per-6-guanidino-CDs have a $\mathrm{p} K_{\mathrm{a}} \cong 12$ (20) therefore they are fully protonated at neutral $\mathrm{pH}$, unlike the corresponding per-6amino-cyclodextrins which are only partly protonated at neutral $\mathrm{pH}(21)$ owing to $\mathrm{p} K_{\mathrm{a}} \cong 8$. In order to facilitate solubility in DMSO the product was converted to its picrate salt, bguan.picrate (Supplementary Figure S3). [6-(2-Aminoethyl phosphate)-6-deoxy]- $\beta$-cyclodextrin (bphos.Na), a $20 \%$ phosphorylated water soluble CD derivative (Scheme 1c) was prepared in 30\% yield after reaction of heptakis[6-bromo-6-deoxy]- $\beta$-cyclodextrin (water insoluble) with 2-aminoethyl dihydrogen phosphate at $80^{\circ} \mathrm{C}$ under pressure $\left(10\right.$ atm $\left.\mathrm{N}_{2}\right)$ in DMF (Supplementary Figure S4). ${ }^{31} \mathrm{P}$ NMR spectra confirmed the presence of aminoethyl phosphate groups in the product, since two broad ${ }^{31} \mathrm{P}$ signals at frequencies different than that of the starting reagent were observed (Supplementary Figure S5). The product was subsequently converted in situ in DMSO to

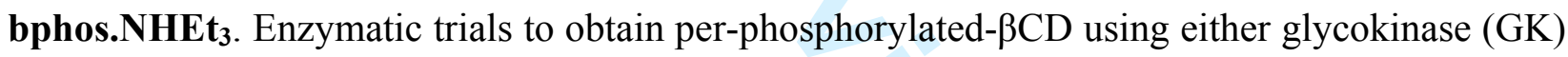
or hexokinase (HK), employed using protocols for the conversion of $\alpha$-D-glucose to $\alpha$-D-glucose6-phosphate $(22,23)$ were not successful using natural $\beta C D$ as the substrate. In spite of its partial phosphorylation bphos. HHEt $_{3}$ was included in the study in order to roughly estimate the binding of the phosphate groups with their guanidinium counterparts.

In all the above cases, the anionic groups are connected to the $\beta C D$ core via two or three bond linkers. On the contrary the guanidino groups are grafted directly on the narrow CD periphery thus are pre-organized and their spatial freedom is limited.

\section{${ }^{1} \mathrm{H} N M R$ studies in DMSO-d $\mathrm{d}_{6}$ and DMSO-d $\mathrm{d}_{6} / \mathrm{H}_{2} \mathrm{O}(\mathrm{80} / 20, \mathrm{v} / \mathrm{v})$ solution}

The ${ }^{1} \mathrm{H}$ NMR signals of the guanidinium group $\left[-\mathrm{C} 6 \mathrm{NH}(=\mathrm{NH}) \mathrm{NH}_{2} \cdot \mathrm{H}^{+}\right.$] were monitored during

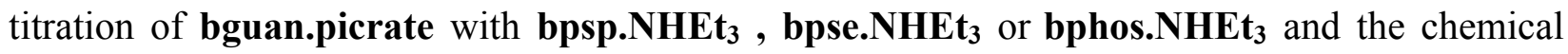
shift changes were plotted against the equivalents of the titrants added (Figure 1). The graphs 
display a fast growing part, a clear change of slope near the points where one equivalent of titrant has been added and subsequently a plateau, thus indicating 1:1 interaction between the positively and negatively charged CD partners. Blank experiments, i.e. self-titrations of each of the components, did not result in change of the peaks therefore homodimers are not formed. It follows that the apparently strong binding is due to the formation of heterodimers via electrostatic and H-bonding interactions between guanidinium and carboxylate groups (1). The curves appear to be sigmoidal, most clearly in the plot of bguan.picrate/bpsp.NHEt $\mathbf{t}_{3}$ in DMSO- $d_{6}$ (Figure 1a), indicating cooperative binding behavior (24). Likewise, the titration plot for the same interacting pair obtained by recording the ${ }^{13} \mathrm{C}$ NMR chemical shift changes of the carbon atom $\mathrm{C} 6$ next to the guanidinum group, also had an unambiguous sigmoidal shape.

$<$ Figure 1>

In order to quantify these observations the NMR data were fitted to a general "DoseResponse" function (see experimental part, equation 1) that provides an estimation of $h$, the Hill coefficient that is interpreted as an index of cooperativity (24) for 1:1 interactions. The calculated $h_{i}$ values, $3.13 \pm 0.31$ and $1.68 \pm 0.20$ (Table 1) for bguan.picrate/bpsp. NHEt $_{3}$ indicate positive cooperativity for binding in both DMSO- $d_{6}$ and DMSO- $d_{6} / \mathrm{H}_{2} \mathrm{O}$, respectively. The pair bguan.picrate/bpse.NHEt ${ }_{3}$ having $h=1.04 \pm 0.12$ and $h=1.28 \pm 0.06$, respectively in the two solvent systems, shows rather non-cooperative behavior whereas data of bguan.picrate/bphos.NHEt ${ }_{3}$, can not be used (and will not be used thereafter) to extract quantitative results. shows cooperativity ( $h$ is $1.67 \pm 0.11$ ) in spite of incomplete phosphorylation of the primary side of bphos.NHEt $t_{3}$

\section{Fitting of NMR titration data and calculation of binding constants.}

In order to extract binding constants fittings to equation 2 that describes binding for 1:1 systems in fast exchange in NMR spectroscopy $(25,26)$ and to its simplified form 3 , according to the 
Eadie-Hofstee approximation (24) $\left[\left(\Delta \delta_{\mathrm{i}} / \Delta \delta_{\max }\right) \mathrm{C} \rightarrow 0\right]$ were attempted, where $\Delta \delta_{\mathrm{i}}$ is the observed difference of the chemical shifts, $\Delta \delta_{\max }$ is the maximum difference of the chemical shifts, $\mathrm{X}$ is the concentration of the titrant added, $\mathrm{C}$ is the concentration of the component held constant and $K$, $K_{\mathrm{D}}\left(K=K_{\mathrm{D}}^{-1}\right)$ are the association and the dissociation constants, respectively.

$$
\begin{gathered}
{[\mathrm{X}]=\left(\Delta \delta_{\mathrm{i}} / \Delta \delta_{\max }\right)\left[\mathrm{C}+\left(K \cdot\left(1-\left[\Delta \delta_{\mathrm{i}} / \Delta \delta_{\max }\right]\right)^{-1}\right]\right.} \\
\text { or } \quad \Delta \delta_{\mathrm{i}}=-K_{\mathrm{D}} \cdot\left(\Delta \delta_{\mathrm{i}} /[\mathrm{X}]\right)+\Delta \delta_{\max }
\end{gathered}
$$

Fitting of the data to either equation was unsuccessful, however the data were satisfactorily fitted (Figure 2) to the linear Hill equation 4 (24), where $\mathrm{Y}=\Delta \delta_{\mathrm{i}} / \Delta \delta_{\max }$ :

$$
\log [\mathrm{Y} /(1-\mathrm{Y})]=-\log K_{\mathrm{D}}+h_{i i} \log \mathrm{X}
$$

The results, although with considerable errors, give an estimation of the binding constants, listed in Table 1. The highest $h_{\mathrm{ii}}$ and $K_{\mathrm{a}}$ values are observed for bguan.picrate/bpsp.NHEt $\mathbf{t}_{3}$ in DMSO. The coefficients $h_{\mathrm{ii}}$ calculated from equation 4 are greater than 1 in all cases, confirming positive cooperativity in the supramolecular assembly of the pairs to a stoichiometric capsule. These ebservations apply also to the system bguan.pierate/bphos.HNEt $t_{3}\left(h_{i i}-1.14, K_{a}-0.34 \times 10^{-4} \mathrm{M}^{-}\right.$ ( $\left.\mathrm{R}^{2}-0.989\right)$ although these values are not exact, shown only to demonstrate the formation of heterodimers is possible even with partially phosphorylated CDs. This behaviour could be explained by considering a model where the first guanidinium-carboxylate binding event at glucopyranose unit A of bguan.picrate is followed by sequential binding at adjacent units (B, C...) facilitated by local conformational changes of the carboxylate linkers of bpse or bpsp that result in accelerating the binding rate until this "zipping" process is completed. Increase of the carboxylate- $\mathrm{CD}$ concentration during the titration of bguan.picrate favors this "dimerisation by zipping" mechanism over other oligomerisation or polymerization processes thus giving a sigmoidal binding curve. It follows that the binding equation 2 , that assumes a linear relationship between the binding rate and titrant concentration, cannot be satisfactorily applied to fit the data.

$<$ Figure 2, Table 1> 


\section{Isothermal Titration Calorimetry in DMSO solution}

ITC is frequently used to calculate thermodynamic parameters and binding constants in cyclodextrin systems (8). The sample, placed in a cell with adiabatic walls is titrated automatically with a titrant's solution. The heat change recorded during the titrations, compared to a reference sample, is translated to an enthalpy change $v s$ titrant's molar ratio plot. For the present supramolecular systems data plots obtained in mixtures of $\mathrm{DMSO} / \mathrm{H}_{2} \mathrm{O}(80 / 20, \mathrm{v} / \mathrm{v})$ gave non-reproducible results due to large background noise, evidently owing to strong DMSO-water exothermic association which is very much dependent on the exact composition of the mixture (27). Thus, ITC data were obtained only in pure DMSO solutions and were analyzed by fitting to the function used for 1:1 interacting systems built in Microcal Origin software. The results are shown in Table 2.

$<$ Figure 3, Table 2>

The values of $K_{\mathrm{a}}$ obtained from ITC are similar to the ones calculated from NMR data (Table 1) and the stoichiometry was confirmed 1:1, showing that both methods reflect the same types of interactions, i.e. charge-charge, dipole-dipole and H-bonding, in pure DMSO. The processes are exothermic and the $\Delta \mathrm{G}$ values are high. A sizeable negative entropy contribution in both cases signifies formation of well ordered supramolecular structures. Thus NMR and calorimetric titration results both indicate formation of heterodimers between the fully cationic bguan and the fully carboxylated or the partially phosphorylated cylodextrins, bpsp, bpse and bphos, in DMSO (NMR, ITC) and in DMSO/ $\mathrm{H}_{2} \mathrm{O}(80 / 20$, v/v or \% 50.4/49.6 \% mole) (NMR). There is strong binding of bguan.bpsp in DMSO $(\log K \sim 5)$ which decreases in $\mathrm{DMSO} / \mathrm{H}_{2} \mathrm{O}$ $(\log K \sim 4)$ or with shortening of the chain connecting the carboxylate groups to the CD torus by one methylene group (bpse). Introduction of water lessens the H-bonding directed ion pairing, whereas the optimal spatial arrangement of the interacting groups is also important, as expected. The present $\Delta \mathrm{H}$ values of $\cong 12 \mathrm{~kJ} \mathrm{~mol}^{-1}$ per glucopyranose unit compare well with literature calorimetric data obtained for model guanidinium - carboxylate systems in DMSO $(\Delta \mathrm{H}=15.06$ 
$\left.\mathrm{kJ} . \mathrm{mol}^{-1}\right)$ (28) where planarity was structurally imposed in the two interacting charged molecules. In the same study (28) it was additionally demonstrated that when the counter-ion of the guanidinium species was changed from chloride to tetraphenyl borate and then to acetate the binding constant almost doubled (28). The latter observation can be rationalized if one considers that soft-soft ion pairs interact more favorably than soft-hard ones, according to Pearson's hardsoft [Lewis] acid - base principle (29). In the present interacting systems with soft counter-ions, picrate and triethyl ammonium, the anticipated favorable overall effect is reflected in the high binding constants. The ionic capsule between amidinium and carboxylate calyx[4]arenes has been reported (3) to assemble in water with $K_{\mathrm{a}} \cong 3.3 \cdot 10^{-4} \mathrm{M}^{-1}$, a value close to the ones reported for our cyclodextrins in $\mathrm{DMSO} / \mathrm{H}_{2} \mathrm{O}$. Previous potentiometric titrations $(30,31)$ between carboxy and amino cyclodextrins in water afforded $\log K_{\mathrm{a}} \sim 10$ (30) and 8.5 (31). The displayed cooperativity in the present binding cases could be anticipated to promote stronger binding and association constants higher than the measured $\sim 10^{5}$, given that the interacting charged groups reside in a rigid circle on the macrocycle of the CDs. Apparently the ease of approach of the two oppositely charged macrocycles, the efficiency of solvation of the large counter ions and the degree of organization between the seven interacting ion couples is effective but not absolutely optimal in the narrow $\mathrm{CD}$ region. Our results also indicate that the binding would be much stronger if the perphosphorylated CDs were available for testing.

\section{Conclusions}

Heterodimers are efficiently and cooperatively formed between a guanidino cyclodextrin and two carboxylated as well as one partially phosphorylated cyclodextrin, a result of Coulomb and H-bonding interactions. The stoichiometry is $1: 1$ in all cases and the association is characterised by high stability in DMSO that weakens in $\mathrm{DMSO} / \mathrm{H}_{2} \mathrm{O}$, positive cooperativity indicating multivalency effects, negative enthalpy of formation, $\Delta \mathrm{H}$, and sizeable negative entropy, $\Delta \mathrm{S}$, indicating formation of very ordered supramolecular structures.

\section{$<$ Scheme 2>}




\section{Experimental}

\section{Synthesis}

General

Heptakis(6-bromo-6-deoxy)- $\beta$-cyclodextrin (32), heptakis(6-azido-6-deoxy)- $\beta$-cyclodextrin (33, 10), heptakis(6-amino-6-deoxy)- $\beta$-cyclodextrin $(33,10)$ and heptakis(6-guanidino-6-deoxy)- $\beta$ cyclodextrin hydrochloride (bguan.HCl) (10), were prepared using literature procedures. Likewise, heptakis[6-(3-thiopropionate-6-deoxy]- $\beta$-cyclodextrin, sodium salt (bpsp.Na, 71\%) and heptakis[6-thioethanoate-6-deoxy)- $\beta$-cyclodextrin, sodium salt (bpse.Na, 89\%) were synthesized according to the published procedures (19).

\section{The salt bguan.picrate}

It was received after addition of solid bguan.HCl to an aqueous solution of picric acid. The copious precipitate that was formed was filtered and recrystallised from hot water $(98 \%) .{ }^{1} \mathrm{H}$ NMR (DMSO- $d_{6}, 298 \mathrm{~K}, 500 \mathrm{MHz}$ ): $\delta 8.61$ (s, 14H, picrate) 7.23 (brs, 7H, C6NH) 6.94 (brs, 21H, $\left(\mathrm{C}(=\mathrm{NH}) \mathrm{NH}_{2}\right) 6.20$ (brd, $\left.J=6 \mathrm{~Hz}, 7 \mathrm{H}, \mathrm{OH} 3\right)$ 6,03 (brs, 7H, OH2) 4.89 (brs, 7H, H1) 3.823.80 (brd, 7H, H5) 3.71-3.69 (brd, 7H, H3). ${ }^{13} \mathrm{C}$ NMR (DMSO- $\left.d_{6}, 125 \mathrm{MHz}\right) \delta 162.10$ $(\mathrm{C}(=\mathrm{NH}) \mathrm{NH}), 158.46$ (picr), 141.87 (picr), 126.69 (picr), 102.98 (C1), 82.56 (C4), 73.20 (C5), 72.68 (C2), 70.51 (C3), 42.50 (C6, obscured by residual DMSO signal). Anal. Calcd. for $\mathrm{C}_{49} \mathrm{H}_{91} \mathrm{O}_{28} \mathrm{~N}_{21} .7 \mathrm{C}_{6} \mathrm{H}_{3} \mathrm{~N}_{3} \mathrm{O}_{7} .7 \mathrm{H}_{2} \mathrm{O}: \mathrm{C}, 34.7 ; \mathrm{H}, 4.0 ; \mathrm{N}, 18.7 \%$. Found: C, 35.2; H, 4.3; N, 17.5.

\section{The salt bpsp.NHEt ${ }_{3}$}

It was prepared in situ in a DMSO- $d_{6}$ solution using the acid bpspH (Anal. Calcd. for $\mathrm{C}_{63} \mathrm{H}_{98} \mathrm{O}_{42} \mathrm{~S}_{7} . \mathrm{NaCl} .7 \mathrm{H}_{2} \mathrm{O}: \mathrm{C}, 39.1 ; \mathrm{H}, 5.8 \%$. Found: $\left.\mathrm{C}, 38.7 ; \mathrm{H}, 6.0\right)$ received from a Sephadex column after washing bpsp.Na with water acidified with $\mathrm{HCl}$ to $\mathrm{pH} 2.3$, and seven equivalents of triethylamine: ${ }^{1} \mathrm{H}$ NMR (DMSO- $\left.d_{6}, 298 \mathrm{~K}, 500 \mathrm{MHz}\right) \delta 5.84$ (brs, $\left.14 \mathrm{H}, \mathrm{OH} 2, \mathrm{OH} 3\right), 4.86(\mathrm{~d}, J=$ $2 \mathrm{~Hz}, 7 \mathrm{H}, \mathrm{H1}$ ), 3.79 (br t, $J=7 \mathrm{~Hz}, 7 \mathrm{H}, \mathrm{H} 5), 3.61$ (t, $J=9 \mathrm{~Hz}, 7 \mathrm{H}, \mathrm{H} 3$ ) 3.38 (t, $J=9 \mathrm{~Hz}, 7 \mathrm{H}, \mathrm{H} 4$ ), 
$3.32(\mathrm{dd}, J=2 \mathrm{~Hz}, J=9 \mathrm{~Hz}, 7 \mathrm{H}, \mathrm{H} 2), 3.06(\mathrm{~d}, J=12 \mathrm{~Hz}, 7 \mathrm{H}, \mathrm{H} 6), 2.87$ (dd, $J=5 \mathrm{~Hz}, J=12 \mathrm{~Hz}$, 7H, H6’), 2.72 (t, $\left.J=7 \mathrm{~Hz}, 14 \mathrm{H}, \mathrm{H} 7, \mathrm{H} 7{ }^{\prime}\right), 2.55$ (q, $\left.J=7 \mathrm{~Hz}, 42 \mathrm{H},{ }^{\dagger} \mathrm{NH}\left(\mathrm{CH}_{2}\right)_{3}\right), 2.44$ (dd, $J=7$ $\mathrm{Hz}, J=13 \mathrm{~Hz}, 14 \mathrm{H}, \mathrm{H} 8, \mathrm{H} 8$ '), $0.98\left(\mathrm{t}, J=7 \mathrm{~Hz}, 63 \mathrm{H},\left(\mathrm{CH}_{3}\right)_{3}\right) .{ }^{13} \mathrm{C}$ NMR (DMSO-d $\left.6,125 \mathrm{MHz}\right) \delta$ $173.58(\mathrm{C}=\mathrm{O}), 101.83(\mathrm{C} 1), 84.07(\mathrm{C} 4), 72.26(\mathrm{C} 3), 72.08(\mathrm{C} 2), 70.76(\mathrm{C} 5), 45.64\left(\mathrm{CH}_{2}, \mathrm{Et}\right)$, $35.42\left(\mathrm{SCH}_{2}\right), 33.04(\mathrm{C} 6), 28.23\left(-\mathrm{O}=\mathrm{CCH}_{2}\right), 10.24\left(\mathrm{CH}_{3}, \mathrm{Et}\right)$.

\section{The salt bpseNHEt 3}

It was prepared from bpseH (Anal. Calcd. for $\mathrm{C}_{56} \mathrm{H}_{84} \mathrm{O}_{42} \mathrm{~S}_{7} .7 \mathrm{NaCl} .14 \mathrm{H}_{2} \mathrm{O}: \mathrm{C}, 29.1 ; \mathrm{H}, 4.9 \%$. Found: C, 28.9; H, 4.4) in the same manner: ${ }^{1} \mathrm{H}$ NMR (DMSO- $\left.d_{6}, 298 \mathrm{~K}, 500 \mathrm{MHz}\right) \delta 5.79$ (br s, 14H, OH2, OH3), 4.85 (d, J=3 Hz, 7H, H1), 3.81 (br t, 7H, H5), 3.60 (t, $J=9 \mathrm{~Hz}, 7 \mathrm{H}, \mathrm{H} 3$ ), 3.43 (d, $J=9 \mathrm{~Hz}, 7 \mathrm{H}, \mathrm{H} 4), 3.32$ (dd, $J=3 \mathrm{~Hz}, J=9 \mathrm{~Hz}, 7 \mathrm{H}, \mathrm{H} 2$ ), 3.23 (br s, 14H, H7, H7'), 3.06 (d, $J$ $=13 \mathrm{~Hz}, 7 \mathrm{H}, \mathrm{H} 6), 2.88(\mathrm{dd}, J=5 \mathrm{~Hz}, J=13 \mathrm{~Hz}, 7 \mathrm{H}, \mathrm{H6}$ '), 2.59 [br q, $J=7 \mathrm{~Hz}, 42 \mathrm{H}$, $\left.{ }^{+} \mathrm{NH}\left(\mathrm{CH}_{2}\right)_{3}\right], 0.99\left[\mathrm{t}, J=7 \mathrm{~Hz}, 63 \mathrm{H},\left(\mathrm{CH}_{3}\right)_{3}\right] .{ }^{3} \mathrm{C} \mathrm{NMR}\left(\mathrm{DMSO}-d_{6}, 125 \mathrm{MHz}\right) \delta 172.30(\mathrm{C}=\mathrm{O})$, 102.06 (C1), 84.12 (br, C4), 72.56 (C3), 72.28 (C2), 70.68 (C5), $45.43\left(\mathrm{CH}_{2}, \mathrm{Et}\right), 36.47\left(\mathrm{SCH}_{2}\right)$, 33.47 (C6), $9.74\left(\mathrm{CH}_{3}, \mathrm{Et}\right)$.

\section{6-(2-Aminoethylphosphate)-6-deoxy- $\beta$-cyclodextrin, sodium salt ( bphosNa)}

It was obtained after reaction of heptakis(6-bromo-6-deoxy)- $\beta$-cyclodextrin ( $200 \mathrm{mg}, 0.126$ mmol) with an aqueous solution $(3 \mathrm{~mL})$ of 2-aminoethyl dihydrogen phosphate $(177.7 \mathrm{mg}, 1.26$ mmol, 10eq) and triethylamine $(0.35 \mathrm{~mL}, 2.52 \mathrm{mmol}, 20 \mathrm{eq})$ in DMF (6 mL). The mixture was placed into a Parr autoclave at $80^{\circ} \mathrm{C}$ and $\mathrm{N}_{2}(10 \mathrm{Atm})$ for one weak. The product was received after dialysis using a benzoylated cellulose membrane (MWCO 1200) (30\% yield). NMR and MS data proved a $20 \%$ substitution. mp $220-230^{\circ} \mathrm{C} ;{ }^{1} \mathrm{H}$ NMR $\left(\mathrm{D}_{2} \mathrm{O}, 298 \mathrm{~K}, 500 \mathrm{MHz}\right) \delta 5.10$ (br s, 7H, H1), 4.25 - 3.50 (m, 42H, H3, H5, H8, H2, H4, H6), 3.35 (brs, 7H, H7), 2.95 (brs, 7H, H6'). ${ }^{13} \mathrm{C}\left(\mathrm{D}_{2} \mathrm{O}, 298 \mathrm{~K}\right) \delta$ (broad signals) $102.1(\mathrm{C} 1), 81.7$ (C4), $73.0(\mathrm{C} 3), 72.0(\mathrm{C} 5), 71.5(\mathrm{C} 2), 60.8$ (br, C6, C8), 59.4 (C7), 44.2 (C6NH). ${ }^{31} \mathrm{P}$ NMR (D $\left.2 \mathrm{O}, 298 \mathrm{~K}, 202 \mathrm{MHz}, \mathrm{pH}=6.0\right) \delta 3.71$. MALDITOF MS m/z: $1153.6\left(100 \%, \quad \beta C D . \mathrm{H}_{2} \mathrm{O}\right), \quad 1258.4 \quad\left(54 \%, \quad \mathrm{C}_{44} \mathrm{O}_{38} \mathrm{H}_{77} \mathrm{NP}\right), \quad 1382.4 \quad(9 \%$, $\mathrm{C}_{46} \mathrm{O}_{41} \mathrm{H}_{84} \mathrm{~N}_{2} \mathrm{P}_{2}$ ). 


\section{NMR Titrations}

The NMR titrations and self-titrations (molar ratio method) were recorded on a Bruker Avance DRX $500 \mathrm{MHz}$ at $298 \mathrm{~K}$. A solution of bguan.picrate $(3.0 \mathrm{mM}, 500 \mu \mathrm{L})$ in DMSO- $d_{6}$ and DMSO- $d_{6} / \mathrm{H}_{2} \mathrm{O}(80 / 20, \mathrm{v} / \mathrm{v})$, respectively, was titrated with either bpsp.NHEt $\mathbf{t}_{\mathbf{3}}$ or bpse.NHEt $_{\mathbf{3}}$ solution $(30 \mathrm{mM})$ of the same composition. Additions of $5 \mu \mathrm{L}$ were carried out until 1:1 molar ratio and continued with $10 \mu \mathrm{L}$ aliquots of the titrants' solutions until molar ratio 1:3. A bguan.picrate solution $(2.0 \mathrm{mM}, 500 \mu \mathrm{L})$ in DMSO- $d_{6}$ was titrated with a bphos.NHEt $\mathbf{b}_{3}$ solution $(20 \mathrm{mM})$. The additions were carried out in $10 \mu \mathrm{L}$ aliquots until 1:1 molar ratio and in $20 \mu \mathrm{L}$ aliquots until molar ratio 1:3 All titrants' solutions were fixed in the same concentration of bguan.picrate as the solutions being titrated.

\section{NMR Data fitting}

The NMR data were analyzed using the "Dose Response" built-in function below in Origin ${ }^{\circledR} 5.0$ and GraphPad Prism ${ }^{\circledR}$ 1.0, used for 1:1 interactions where $A_{1}$ and $A_{2}$ are the bottom and top asymptotes, respectively, $h$ is the Hill constant and $\mathrm{x}_{0}$ is the value which refers to the point halfway between the bottom and the top of the curve.

$$
y=A_{1}+\left[\left(A_{2}-A_{1}\right) /\left(1+10^{(x 0-x) \cdot h}\right)\right]
$$

\section{Miclocalorimetry}

The ITC measurements were carried out using a MCS-ITC unit by MicroCal Inc., Northampton, USA. The reaction cell with a $1.4 \mathrm{~mL}$ volume was filled with bguan.picrate solution in DMSO $(0.03 \mathrm{mM})$. A $250 \mu \mathrm{L}$ titration syringe was filled with the titrants, bpsp. NHEt $_{3}(0.3 \mathrm{mM})$ and bpse.NHEt $_{3}(0.6 \mathrm{mM})$, at $298 \mathrm{~K}$. Injection experiments of $8 \mu \mathrm{L}$ each were programmed and executed automatically. A time delay of $300 \mathrm{~s}$ was set between the injections and the contents of the sample were stirred throughout the experiment at $400 \mathrm{rpm}$ to ensure thorough mixing. All solutions were degassed under vacuum for $15 \mathrm{~min}$ immediately before measuring. Enthalpies of dilution of host and of guest compounds were determined in separate experiments and subtracted 
from the corresponding experimental host-guest curves, before fitting of the latter. The final calorimetric data were analyzed using the ORIGIN ${ }^{\circledR} 5.0$ software with embedded calorimetric fitting routines.

\section{Acknowledgements}

Financial support to K. Fotiadou by EU Network of Excellence Nano2Life (NMP 3.4.1.2-1, Nanotechnology) is gratefully acknowledged as well as the assistance of Ms. E. Karatairi in the microcalorimetric measurements.

\section{References}

(1) Schug, K. A.; Lindler, W. Chem. Rev. 2004, 105, 67.

(2) Conn, M. M.; Rebek, J., Jr. Chem. Rev. 1997, 97, 1647.

(3) Corbellini, F.; Di Costanzo, L.; Crego-Calama, M.; Geremia, S.; Reinhoudt, D. N. J. Am. Chem. Soc 2003, 125, 9946.

(4) Schmidtchen, F. P.; Berger, M. Chem. Rev. 1997, 97, 1609.

(5) Zadmard, R.; Schrader, T.; Grawe, G.; Kraft, A. Org. Lett. 2002, 4 (10), 1687.

(6) Klarner, F. G.; Schrader, T.; Polkowska, J.; Bastkowski, F.; Talbiersky, P.; Kuchenbrandt, M. C.; Schaller, T.; de Groot, H.; Kirsch, M. Pure Appl. Chem. 2010, 82 (4): , 991.

(7) Rehm, T.; Schmuck, C. Chem. Commun. 2008, 801.

(8) Cyclodextrins and Their Complexes. Chemistry, Analytical Methods, Applications.; Wiley-VCH Verlag GmbH\&Co. KGaA: Weinheim, 2006.

(9) Badjica, J. D.; Nelson, A.; Cantrill, S. J.; Turnbull, W. B.; Stoddart, J. F. Acc. Chem. Res. 2005, 38, 723.

(10) Mourtzis, N.; Eliadou, K.; Aggelidou, C.; Sophianopoulou, V.; Mavridis, I. M.; Yannakopoulou, K. Org. Biomol. Chem. 2007, 5, 125.

(11) Aggelidou, C.; Mavridis, I. M.; Yannakopoulou, K. Eur. J. Org. Chem. 2009.

(12) Kano, K.; Kitae, T.; Shimofuri, Y.; Tanaka, N.; Mineta, Y. Chem. Eur. J. 2000, 6, 2705.

(13) Kano, K.; Hasegawa, H. J. Incl. Phenom. Macrocycl. Chem. 2001, 41, 41.

(14) Eliseev, A. V.; Schneider, H.-J. Angew. Chem. Int. Ed. Engl. 1993, 32, 1331.

(15) Wenz, G.; Strassnig, C.; Thiele, C.; Engelke, A.; Morgenstern, B.; Hegetschweiler, K. Chem. Eur. J. 2008, 14, 7202.

(16) Schwinte, P.; Darcy, R.; O'Keeffe, F. J. Chem. Soc. Perkin Trans. 2 1998, 805.

(17) Hauser, S. L.; Johanson, E. W.; Green, H. P.; Smith, P. J. Org. Lett. 2000, 2, 3575.

(18) CRC handbook of Chemistry and Physics; CRC Press, Inc.: Boca Raton, Florida, 1988.

(19) Adam, J. M.; Bennett, D. J.; Bom, A.; Clark, J. K.; Feilden, H.; Hutchinson, E. J.; Palin, R.; Prosser, A.; Rees, D. C.; Rosair, G. M.; Stevenson, D.; Tarver, G. J.; Zhang, M. J. Med. Chem. 2002, 45, 1806.

(20) Mourtzis, N.; Paravatou, M.; Mavridis, I. M.; Roberts, M. L.; Yannakopoulou, K. Chem. Eur. J. 2008, 14, 4188.

(21) Tagaki, W.; Yano, K.; Yamanaka, K.; Yamamoto, H.; Miyasaka, T. Tetrahedron Lett. 1990, 131, 3897. 
(22) Chenault, H. K.; Mandes, R. F.; Hornberger, K. R. J. Org. Chem. 1997, 62, 331.

(23) Machado de Domenech, E. E.; Sols, a. FEBS Lett. 1980, 119, 174.

(24) Petter, R. C.; Salek, J. S.; Sikorski, C. T.; Kumaravel, G.; Lin, F.-T. J. Am. Chem. Soc 1990, 112, 3860.

(25) Botsi, A.; Yannakopoulou, K.; Hadjoudis, E. Carbohydr. Res. 1993, 241, 31.

(26) Botsi, A.; Yannakopoulou, K.; Perly, B.; Hadjoudis, E. J. Org. Chem. 1995 60, 4017.

(27) Kirchner, B.; Reiher, M. J. Am. Chem. Soc. 2002, 1246206.

(28) Linton, B.; Hamilton, A. D. Tetrahedron 1999, 55, 6027.

(29) Pearson, R. G. J. Am. Chem.Soc. 1963, 85, 3533.

(30) Hamelin, B.; Jullien, L.; Guillo, F.; Lehn, J.-M.; Jardy, A.; De Robertis, L.; Driguez, H. J. Phys. Chem. 1995, 99, 17877.

(31) Schwinte, P.; Holohan, A.; Darcy, R.; O'Keeffe, F. J. Incl. Phenom. Macrocycl. Chem. 1999, 35, 657.

(32) Gadelle, A.; Defaye, J. Angew. Chem. Int. Ed. Engl. 1991, 30, 78.

(33) Ashton, P. R.; Koeniger, R.; Stoddart, J. F.; Alker, D.; Harding, V. D. J. Org. Chem. 1996, 61, 903. 
Table 1. Fitting results of NMR titration data.

\begin{tabular}{|c|c|c|c|c|c|}
\hline \multicolumn{2}{|c|}{ System } & \multirow{3}{*}{$\begin{array}{c}\begin{array}{c}\text { Stoichio- } \\
\text { metry }\end{array} \\
1: 1\end{array}$} & \multicolumn{2}{|c|}{ Hill coefficient } & \multirow{3}{*}{$\begin{array}{l}K_{\mathrm{a}}\left(\mathbf{M}^{-1}\right)\left(\mathbf{R}^{2}\right)^{\mathbf{c}} \\
6.4 \cdot 10^{5}(0.982)\end{array}$} \\
\hline & & & \multirow{2}{*}{$\begin{array}{c}\boldsymbol{h}_{\mathbf{i}}^{\mathbf{a}^{2}} \\
3.13\end{array}$} & \multirow{2}{*}{$\frac{\boldsymbol{h}_{\mathbf{i i}}^{\mathbf{b}^{\mathbf{b}}}}{2.21}$} & \\
\hline bguan.picrate/ & DMSO- $d_{6}$ & & & & \\
\hline bpsp.NHEt ${ }_{3}$ & DMSO- $d_{6} / \mathrm{H}_{2} \mathrm{O}$ & $1: 1$ & 1.68 & 1.77 & $5.9 \cdot 10^{4}(0.978)$ \\
\hline \multirow{2}{*}{$\begin{array}{l}\text { bguan.picrate / } \\
\text { bpse.NHEt }\end{array}$} & DMSO- $d_{6}$ & $1: 1$ & 1.04 & 1.72 & $4.2 \cdot 10^{4}(0.993)$ \\
\hline & DMSO- $d_{6} / \mathrm{H}_{2} \mathrm{O}$ & $1: 1$ & 1.28 & 1.56 & $1.2 \cdot 10^{4}(0.994)$ \\
\hline
\end{tabular}

${ }^{a}$ Obtained from eq. 1 (see experimental part); ${ }^{b}$ obtained from eq. $4 ;{ }^{c}$ goodness of fit. 
Table 2. Binding constants and thermodynamic parameters obtained from ITC (DMSO, $25{ }^{\circ} \mathrm{C}$ ).

\begin{tabular}{|c|c|c|}
\hline $\begin{array}{c}\text { Thermodynamic } \\
\text { parameters }\end{array}$ & bguan.picrate/ bpsp. HEt $_{3}{ }^{a}$ & bguan.picrate/ bpse.NHEt ${ }_{3}{ }^{b}$ \\
\hline $\boldsymbol{K}_{\mathrm{a}}\left(\mathrm{M}^{-1}\right)$ & $4.7 \pm 0.032 .10^{5}$ & $2.4 \pm 0.021 .10^{5}$ \\
\hline $\mathbf{N}^{\mathbf{c}}$ & $0.99 \pm 0.01$ & $0.93 \pm 0.03$ \\
\hline $\mathbf{\Delta} \mathbf{H}\left(\mathrm{kJ} \mathrm{mol}^{-1}\right)$ & $-83.97 \pm 1.04$ & $-82.44 \pm 3.45$ \\
\hline $\mathbf{\Delta S}\left(\mathrm{J} \mathrm{mol}^{-1} \mathrm{~K}^{-1}\right)$ & $-173.19 \pm 3.93$ & $-182.27 \pm 0.20$ \\
\hline$\Delta \mathbf{G}\left(\mathrm{kJ} . \mathrm{mol}^{-1}\right)$ & $-32.36 \pm 2.20$ & $-28.10 \pm 3.55$ \\
\hline
\end{tabular}

${ }^{\mathrm{a}} \mathrm{X}^{2}=84465 ;{ }^{\mathrm{b}} \mathrm{X}^{2}=295652 ;{ }^{\mathrm{c}}$ stoichiometry. 


\title{
List of Schemes and Figures
}

\author{
Scheme 1. (a) Per(6-guanidino-6-deoxy)- $\beta C D s$, (b) per(6-carboxylate-6-deoxy)- $\beta C D S$ and (c) \\ 6-phosphate-6-deoxy- $\beta C D$.
}

Scheme 2. Heterodimer formation between positively and negatively charged cyclodextrins.

Figure 1. NMR titration data plots (chemical shift of guanidinium peak vs equivalents of titrant)

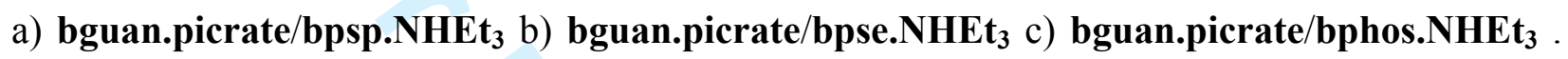
Solid lines correspond to fitting according to equation 1 (see experimental part).

Figure 2. Fitting of the NMR data to the linear equation 4: a) bguan.picrate/bpsp.NHEt $\mathbf{b}_{3}$ in DMSO- $d_{6} / \mathrm{H}_{2} \mathrm{O}$ b) bguan.picrate/bpse.NHEt $\mathbf{t}_{3}$ in DMSO- $d_{6}$ e) bguan.pierate/bphos.NHE $t_{3}$-in PMSO $d_{6:}$

Figure 3. Microcalorimetric titrations in DMSO of a) bguan.picrate with bpsp.NHEt 3 and b) bguan.picrate with bpse.NHEt . $_{3}$ 


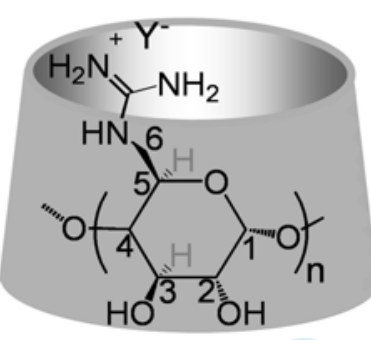

(a) $\mathrm{n}=6,7,8$

bguan: $n=7$

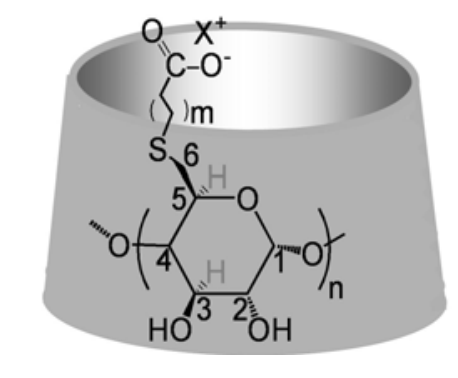

(b) $\mathrm{n}=7, \mathrm{~m}=1,2$ bpse: $\mathrm{m}=1$

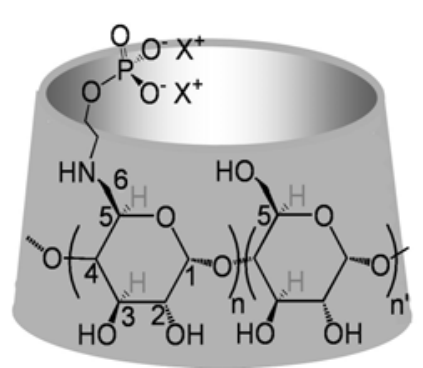

(c) bphos: $\mathrm{n} \approx 2, \mathrm{n}^{\prime} \approx 5$

bpsp: $\mathrm{m}=2$

Scheme 1. 
Scheme 2. 

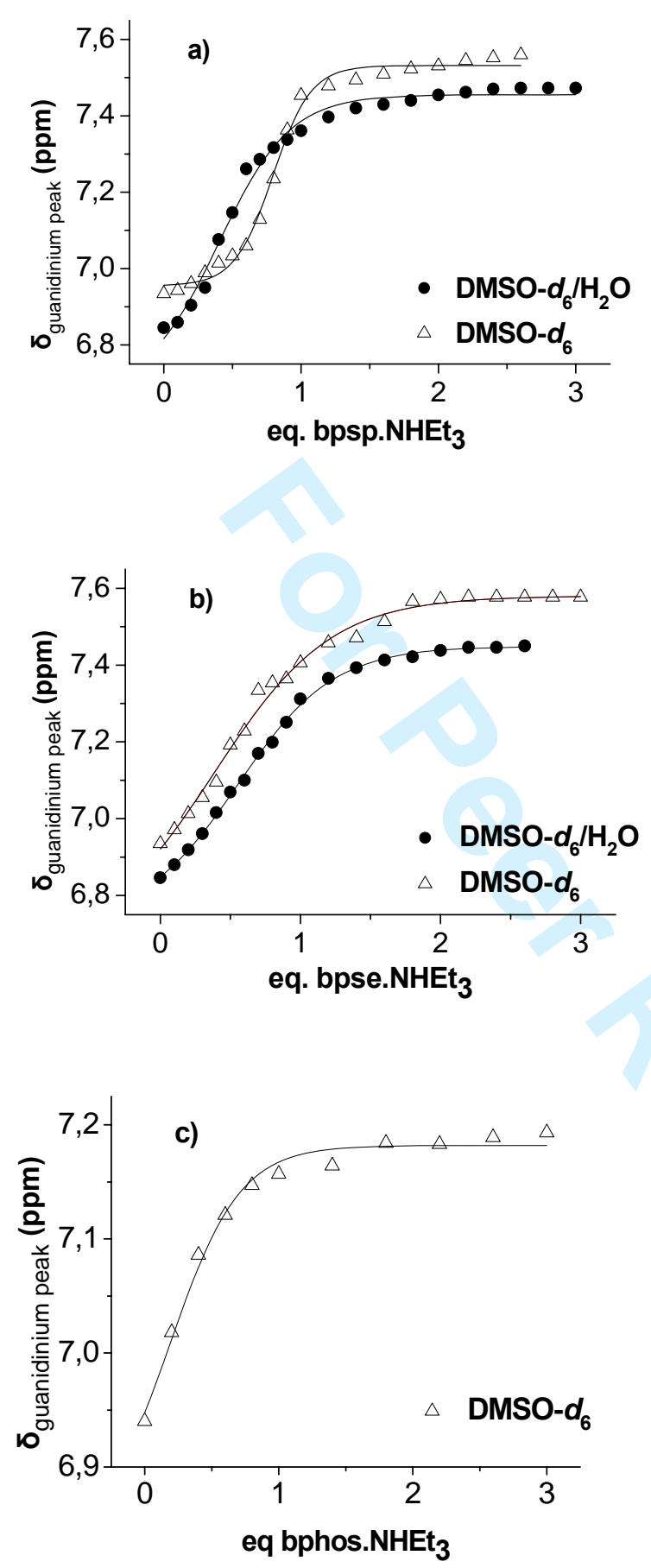

Figure 1. 

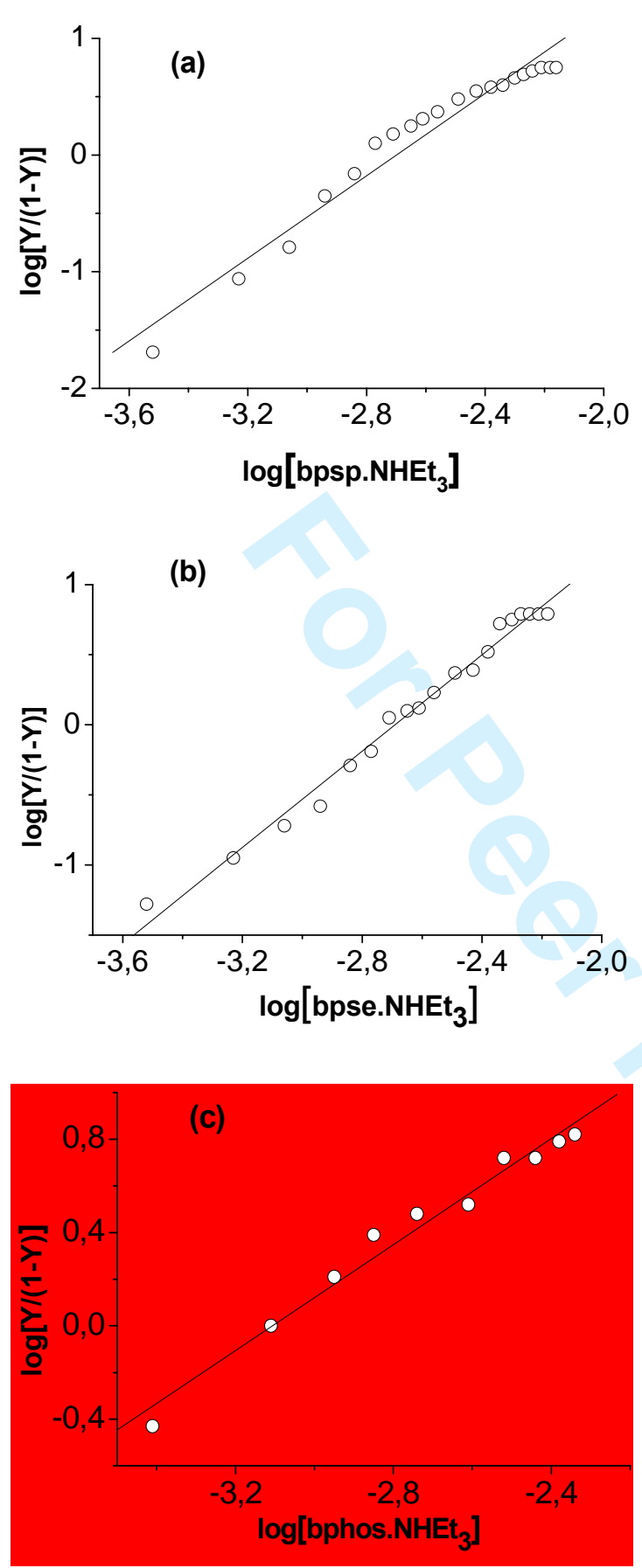

Figure 2. 


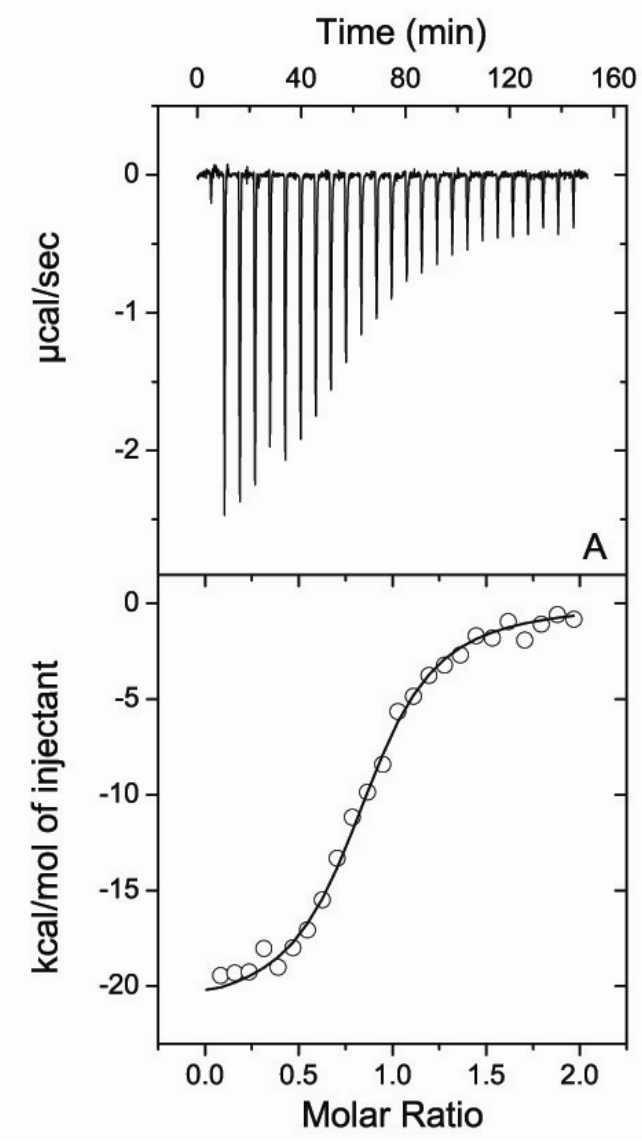

(a)

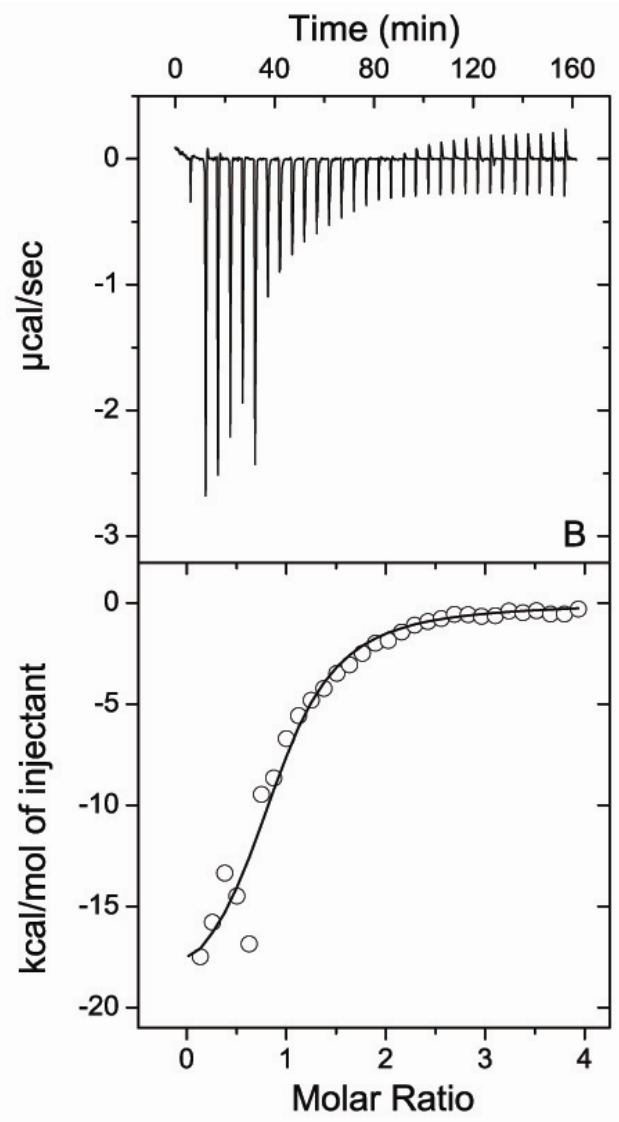

(b)

Figure 3. 


\title{
Cooperative Heterodimer Formation between Per-Guadinylated and Carboxylated or Phosphorylated Cyclodextrins in DMSO and DMSO- Water Studied by NMR Spectroscopy and Microcalorimetry
}

\author{
Katerina Fotiadou, ${ }^{\mathrm{a}}$ Angelos Thanassoulas, ${ }^{\mathrm{b}}$ George Nounesis, ${ }^{\mathrm{b}}$ Konstantina \\ Yannakopoulou $^{\mathrm{a} *}$ \\ ${ }^{a}$ Institute of Physical Chemistry, ${ }^{b}$ Institute of Radioisotopes and Radiodiagnostic \\ Products, National Centre for Scientific Research “Demokritos”, 15310 Aghia \\ Paraskevi, Greece.
}

\section{Supplementary material}

1. Figure $S 1$. (a) bpsp.Na in $\mathrm{D}_{2} \mathrm{O}$ (b) bpsp.HNEt $\mathbf{b}_{3}$ in DMSO- $d_{6}$.

2. Figure S2. (a) ${ }^{1} \mathrm{H}$ NMR and (b) ${ }^{13} \mathrm{C}$ NMR spectrum of bpse.HNEt $_{3}$ in DMSO- $d_{6}$

3. Figure S3. ${ }^{1} \mathrm{H}$ NMR spectrum of bguan.picrate in DMSO- $d_{6}$

4. Figure S4. ${ }^{1} \mathrm{H}$ NMR spectrum in $\mathrm{D}_{2} \mathrm{O}, \mathrm{pH}=6$ of (a) bphos.Na and (b) 2aminoethyl phosphate.

5. Figure S5. ${ }^{31} \mathrm{P}$ NMR spectrum in $\mathrm{D}_{2} \mathrm{O}, \mathrm{pH}=6$ of (a) bphos.Na and (b) 2aminoethyl dihydrogen phosphate 


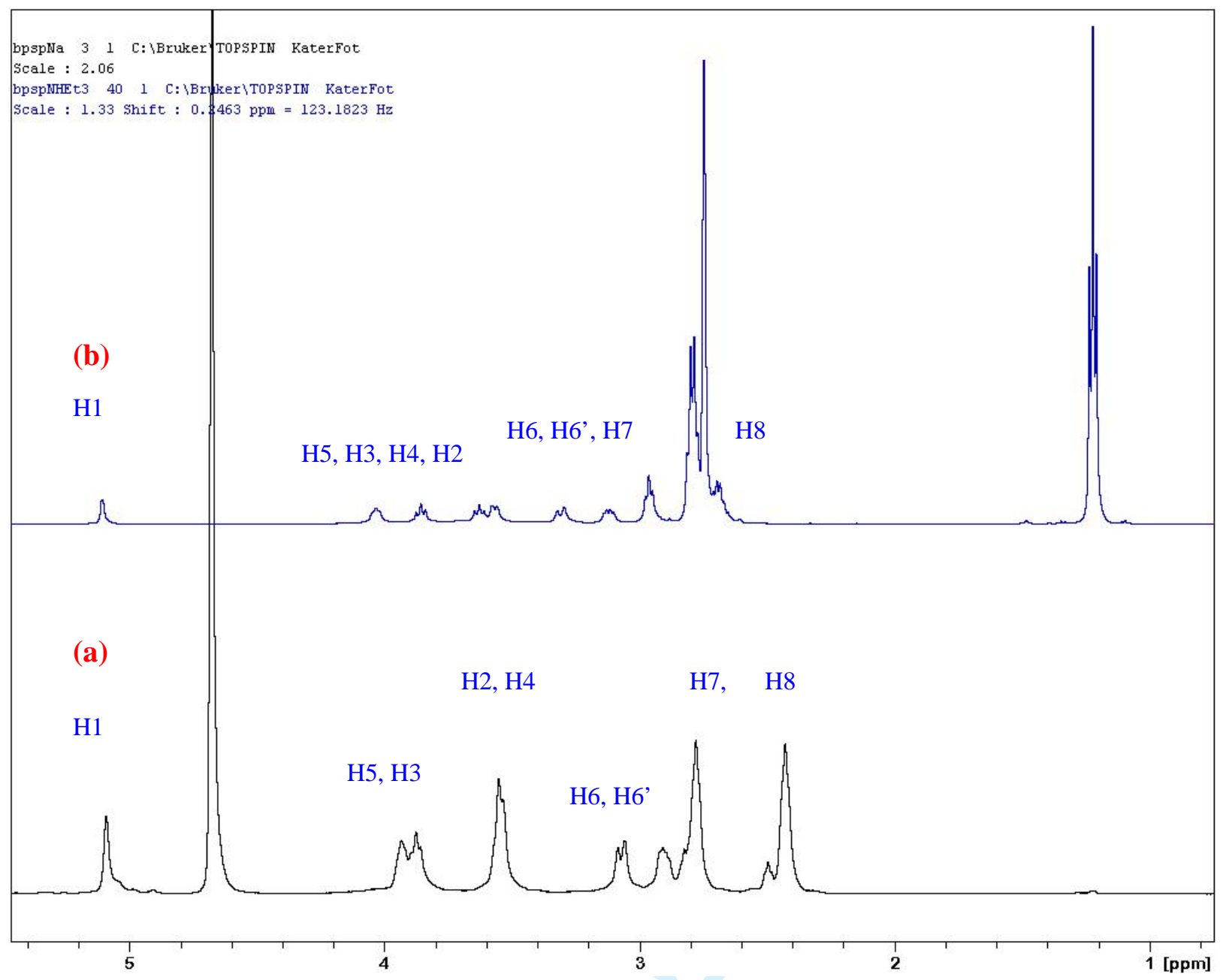

Figure S1. 


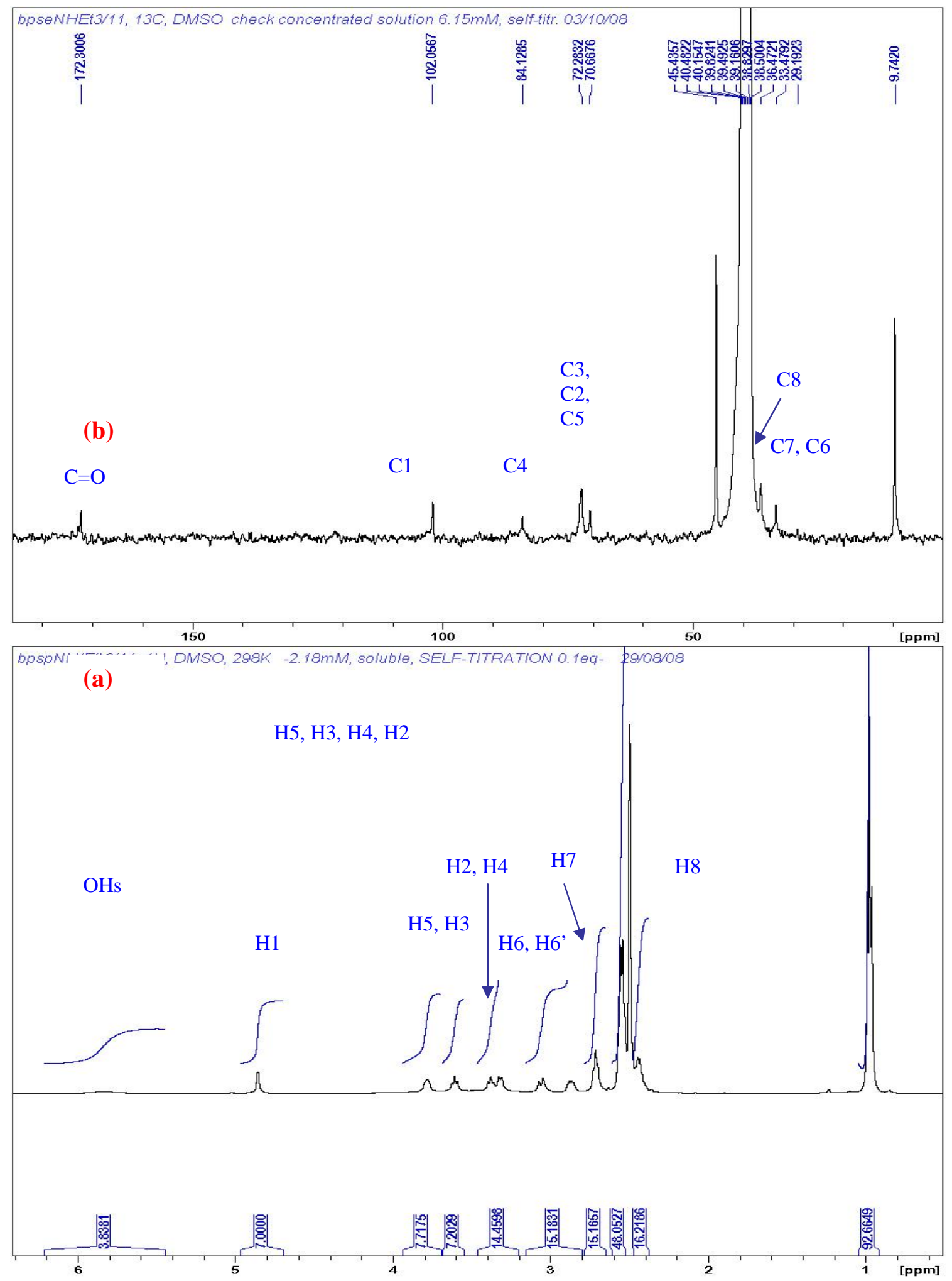

Figure S2. 
(b)

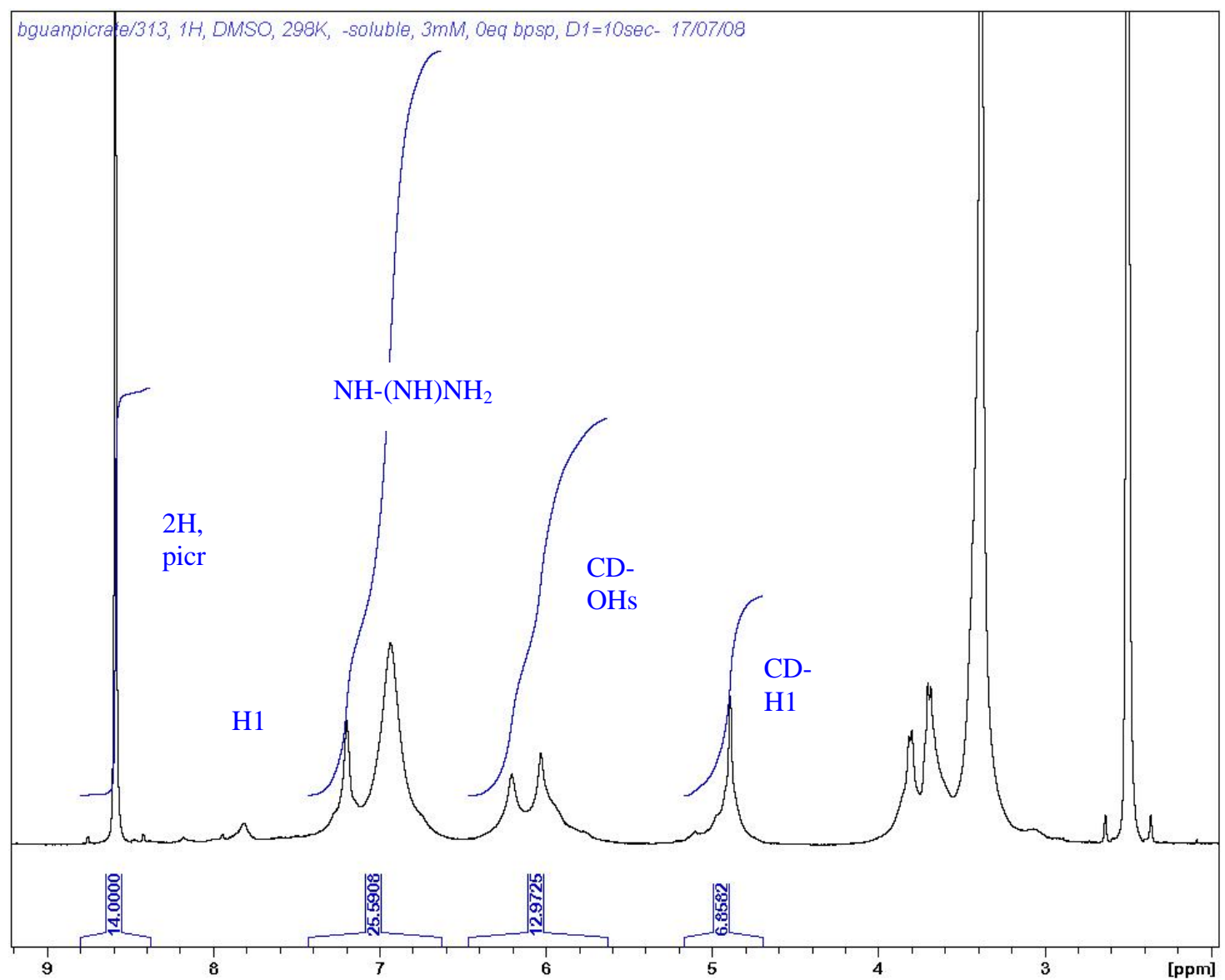

Figure S3. 
(a)

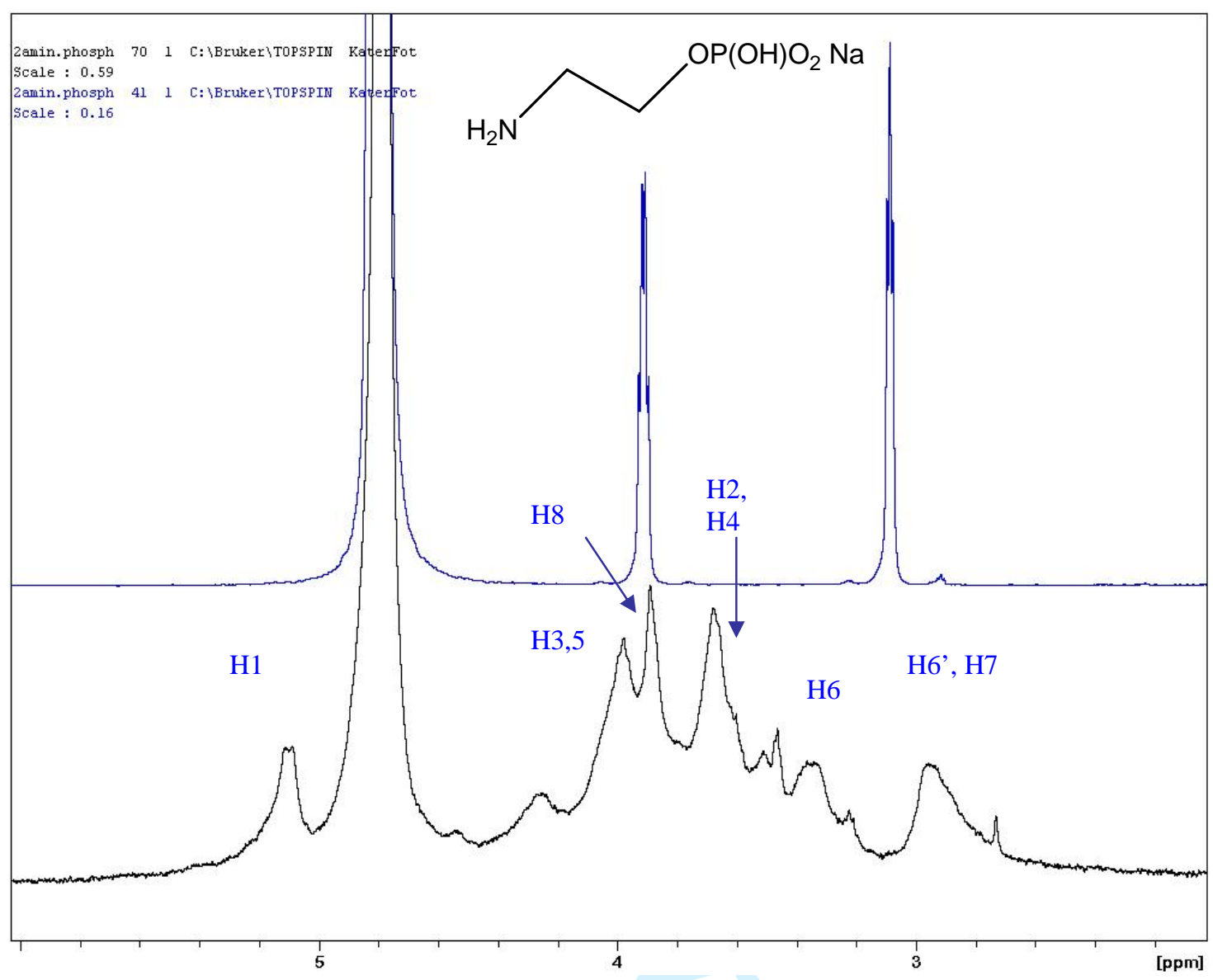

Figure S4. 


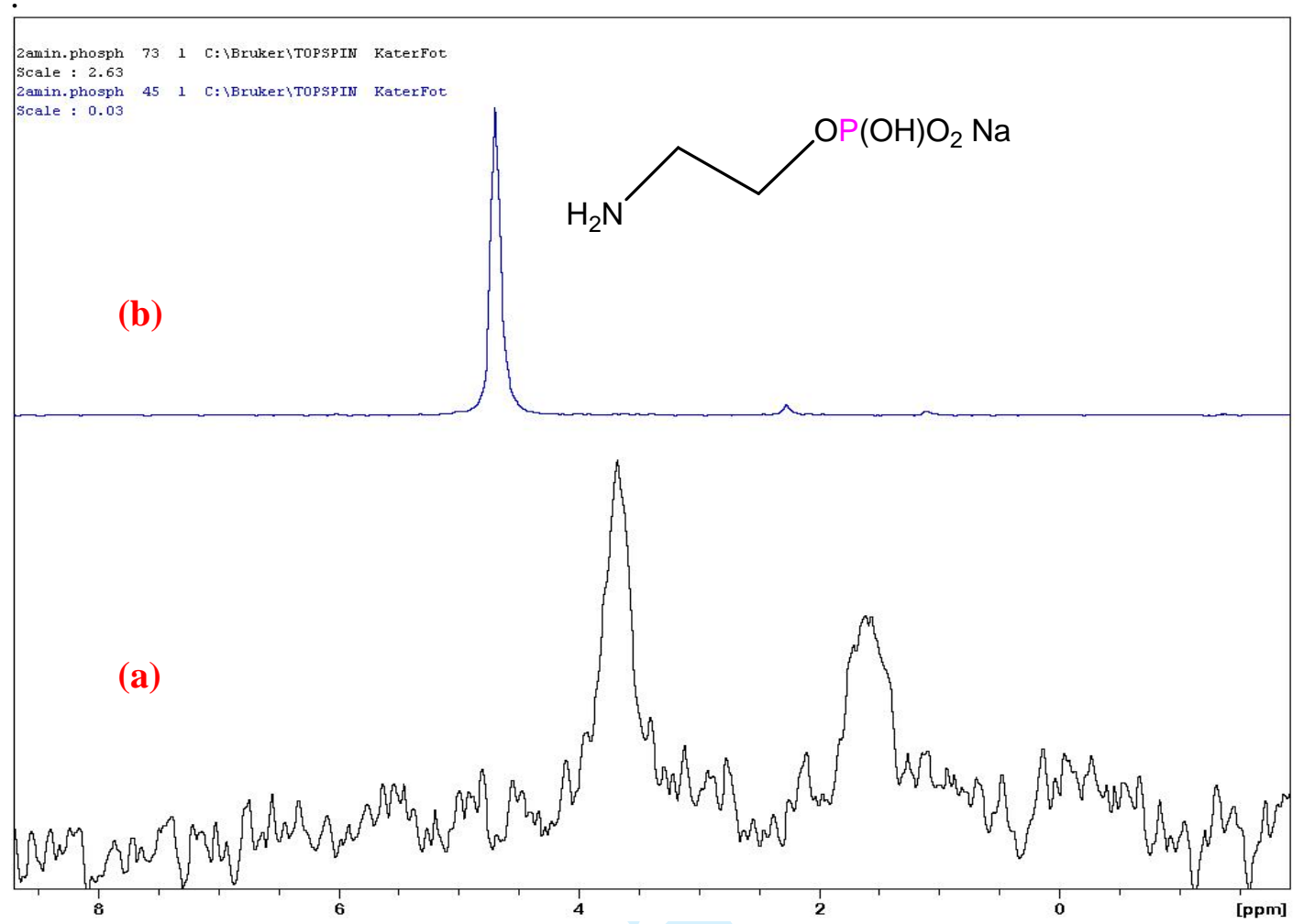

Figure S5. 


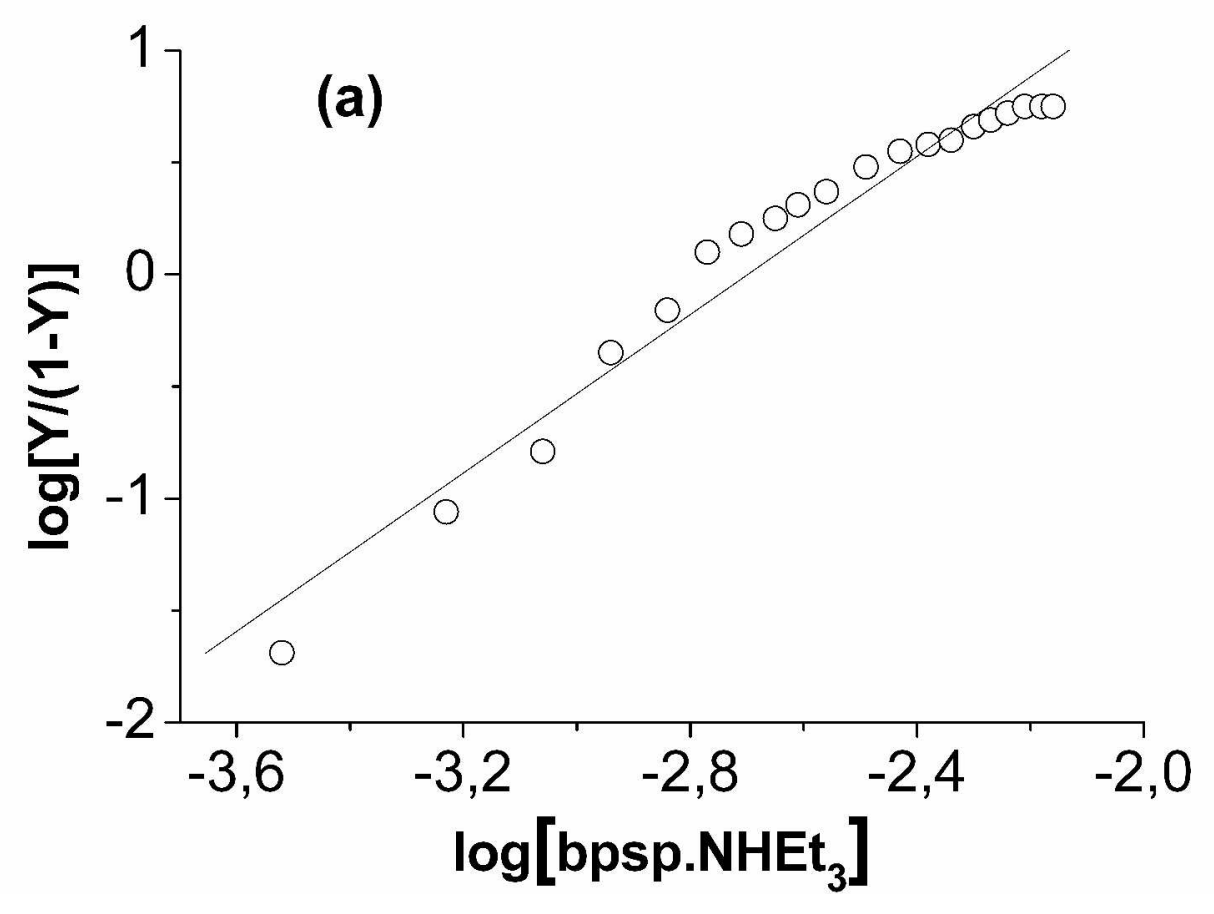

$262 \times 210 \mathrm{~mm}(600 \times 600 \mathrm{DPI})$ 


1
2
3
4
5
6
7
8
9
10
11
12
13
14
15
16
17
18
19
20
21
22
23
24
25
26
27
28
29
30
31
32
33
34
35
36
37
38
39
40
41
42
43
40
45
49
50
51
52
53
55
50

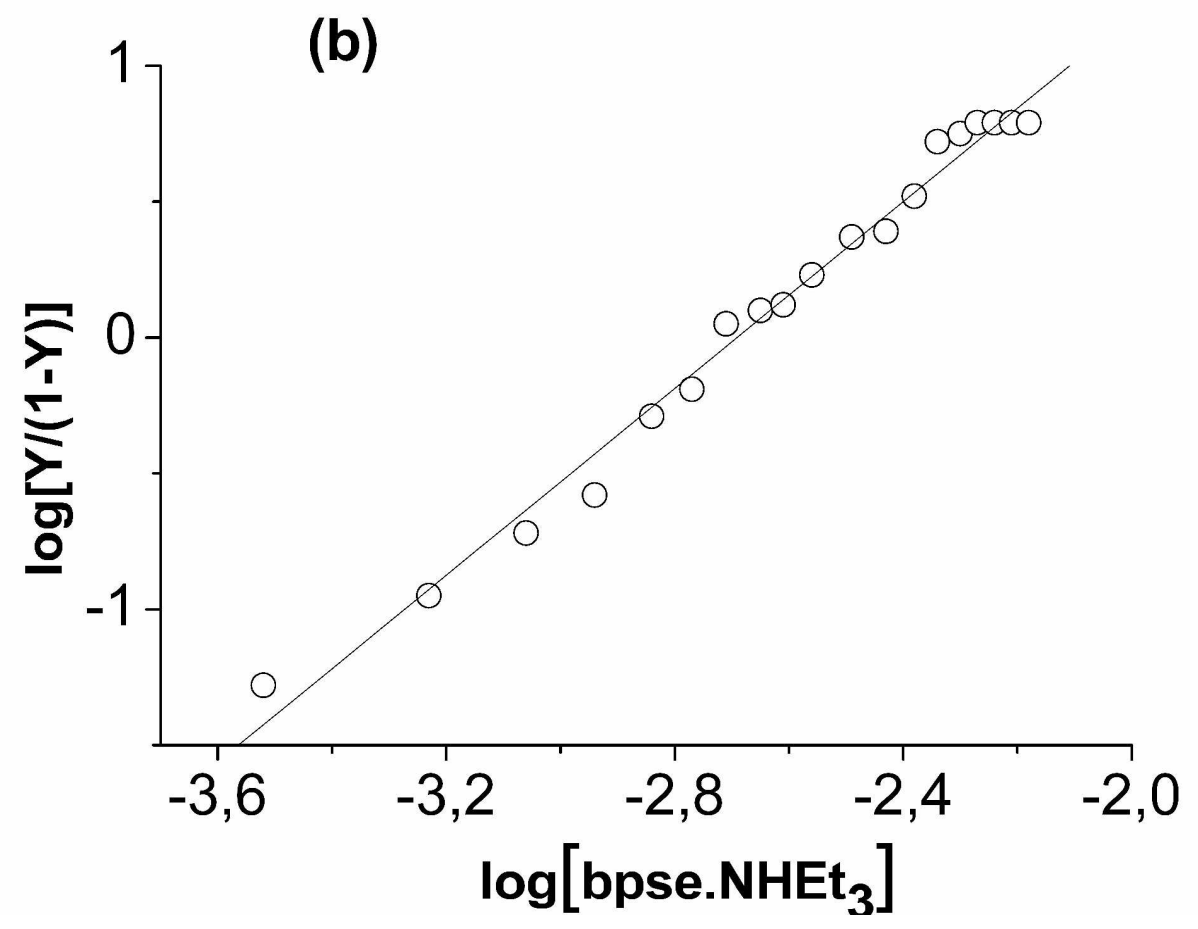

$262 \times 210 \mathrm{~mm}(600 \times 600 \mathrm{DPI})$ 


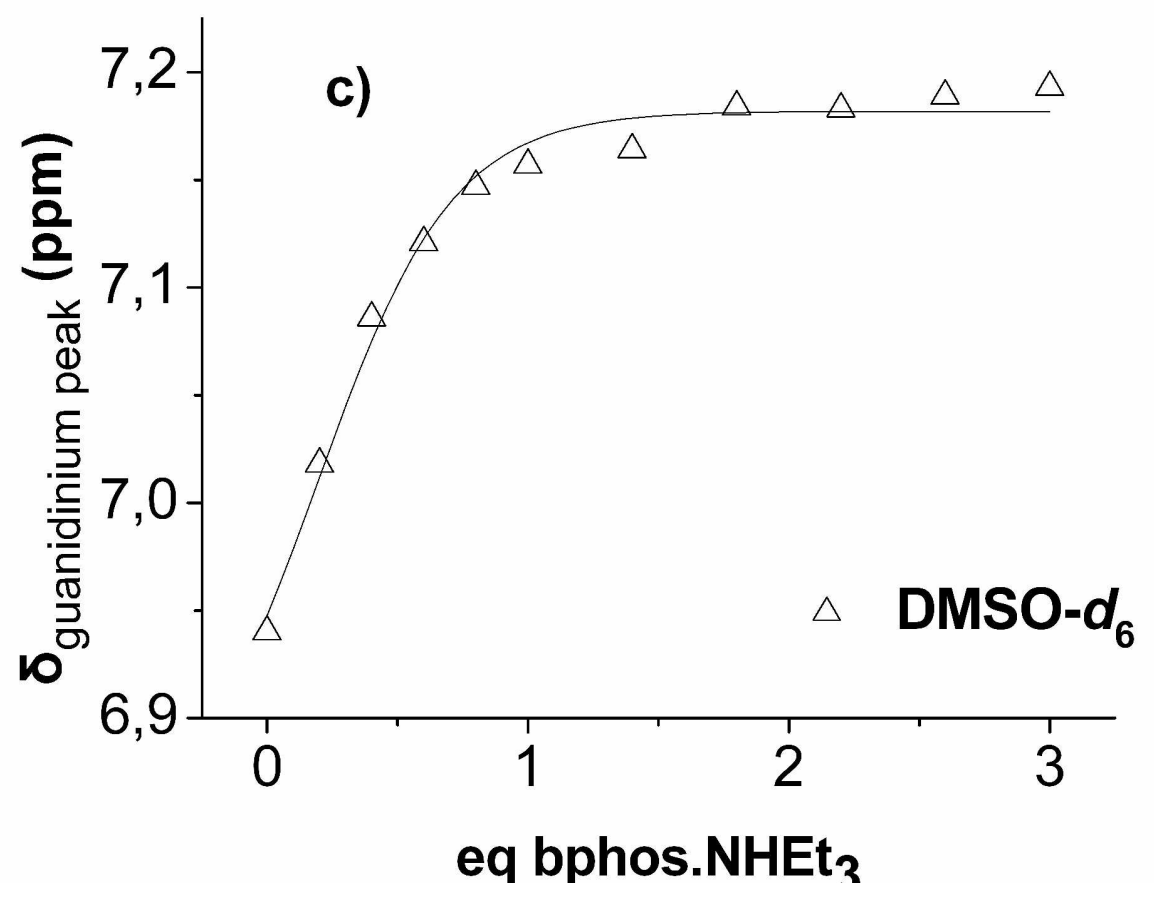

$264 \times 203 \mathrm{~mm}(599 \times 599$ DPI $)$ 


1
2
3
4
5
6
7
8
9
10
11
12
13
14
15
16
17
18
19
20
21
22
23
24
25
26
27
28
29
30
31
32
33
34
35
36
37
38
39
40
41
42
43
40
45
49
50
51
52
53
55
50

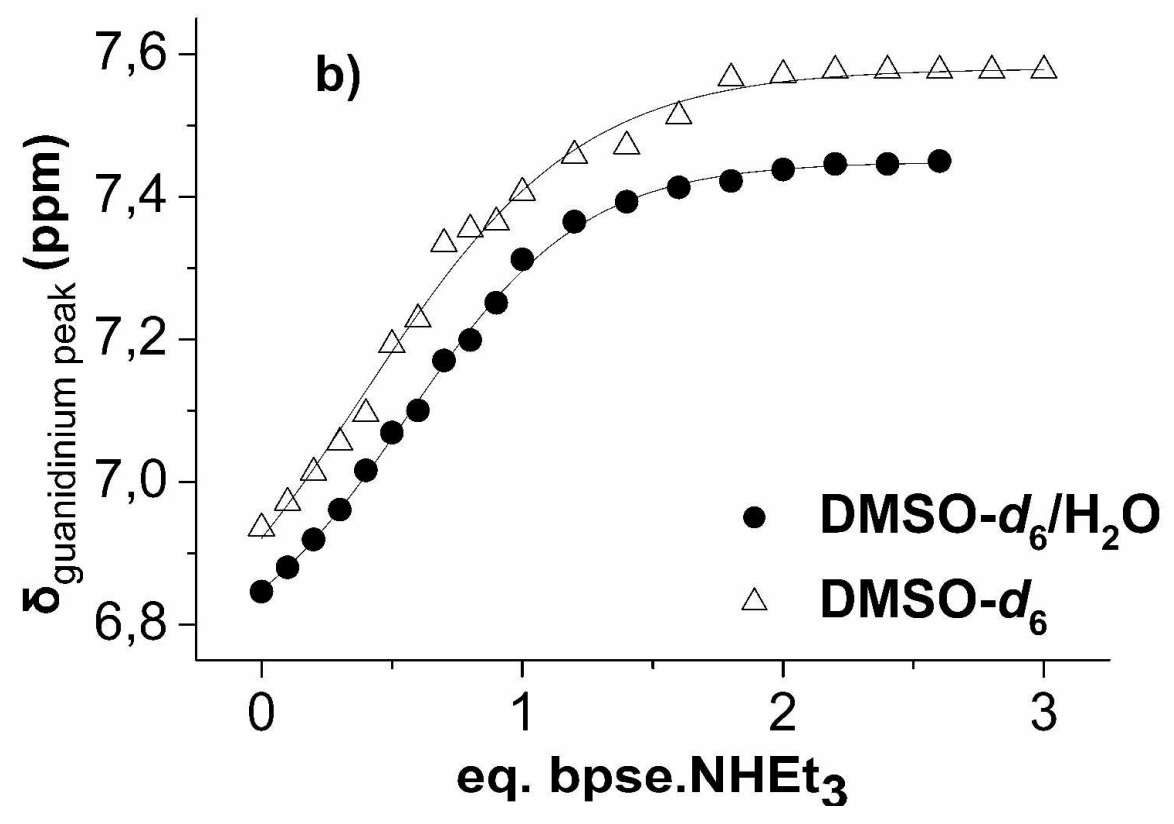

$286 \times 200 \mathrm{~mm}(600 \times 600 \mathrm{DPI})$ 


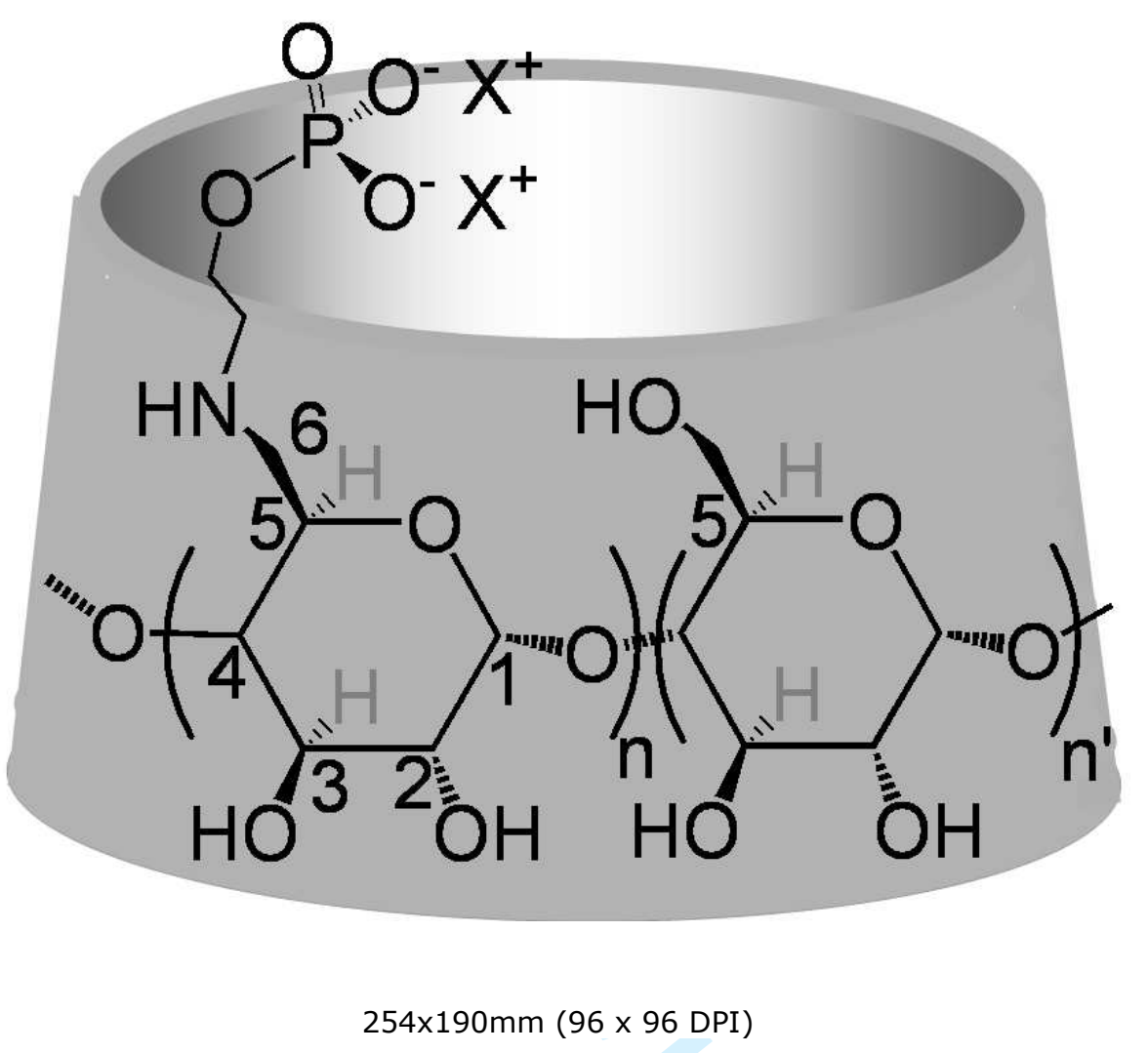

34

35

36

37

38

39

40

41

42

43

44

45

46

47

48

49

50

51

52

53

54

55

56

57

58

59

60

URL: http:/mc.manuscriptcentral.com/tandf/gsch Email: suprachem@mail.cm.utexas.edu 


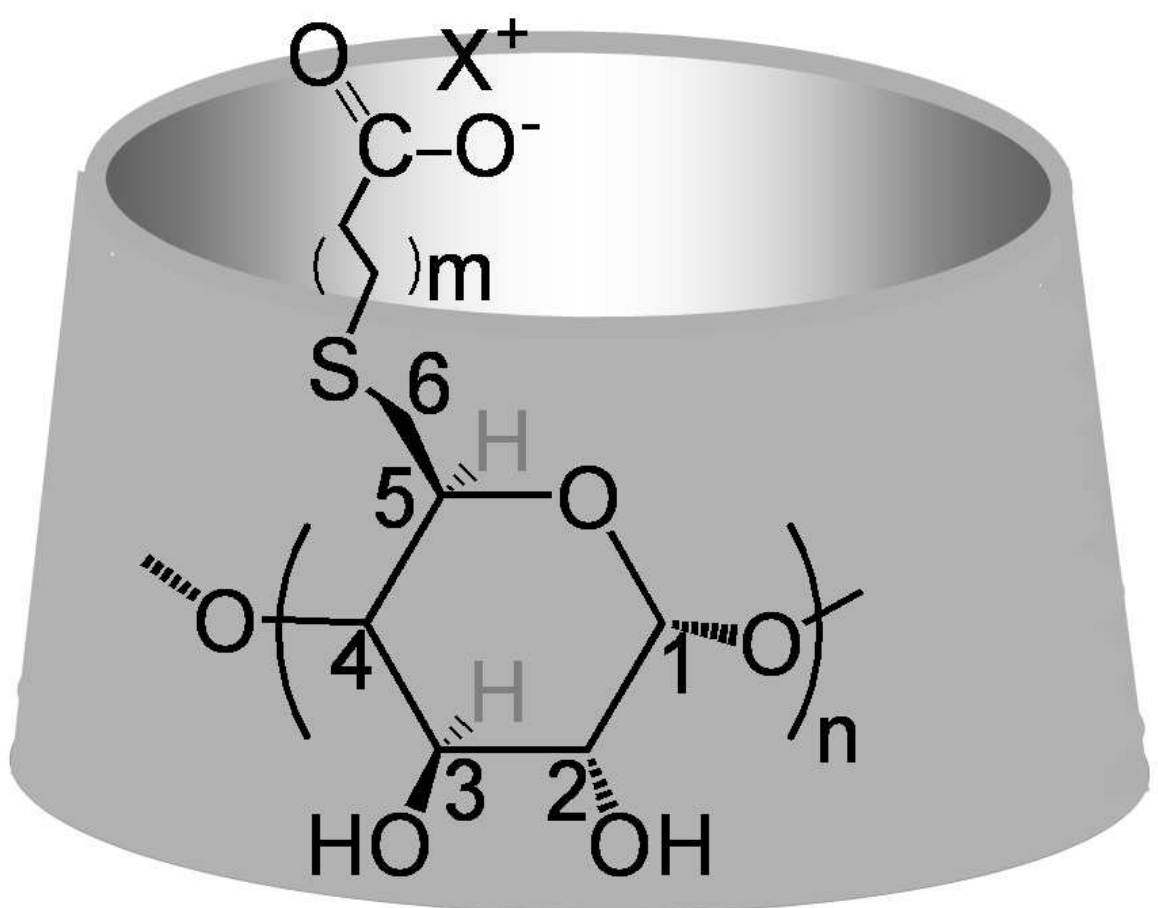

$254 \times 190 \mathrm{~mm}(96 \times 96$ DPI $)$ 


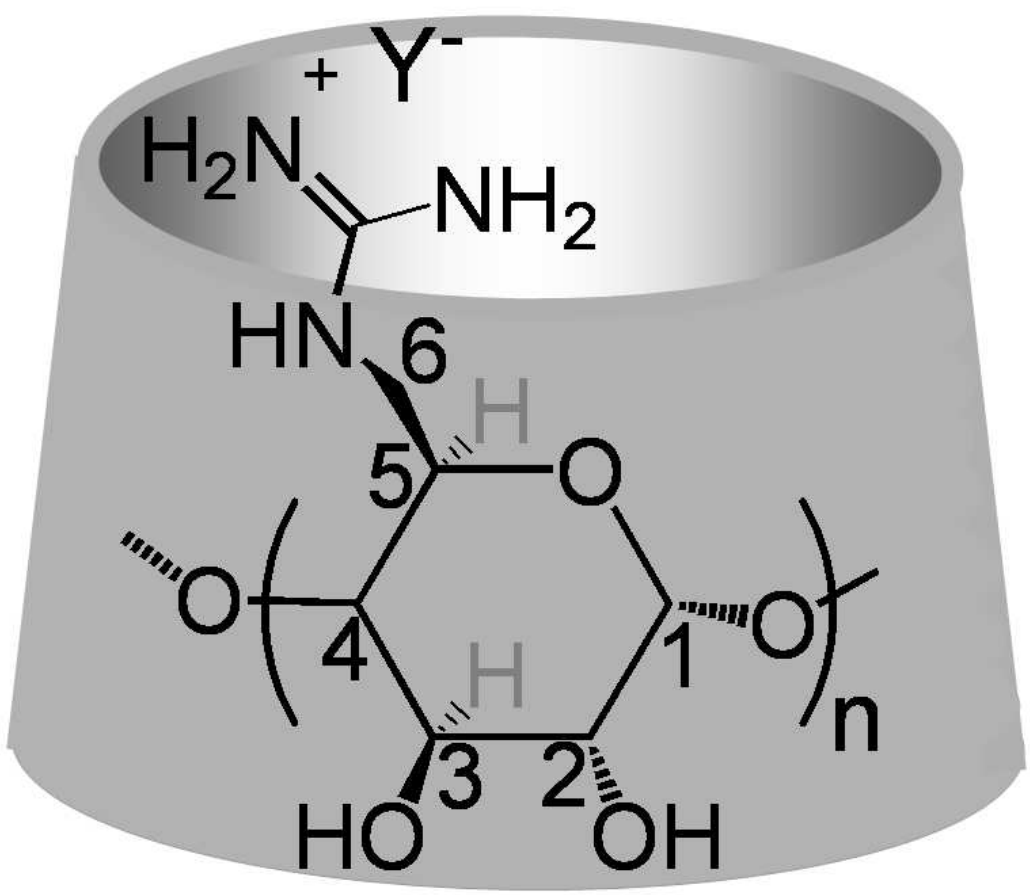

$254 \times 190 \mathrm{~mm}(96 \times 96$ DPI) 


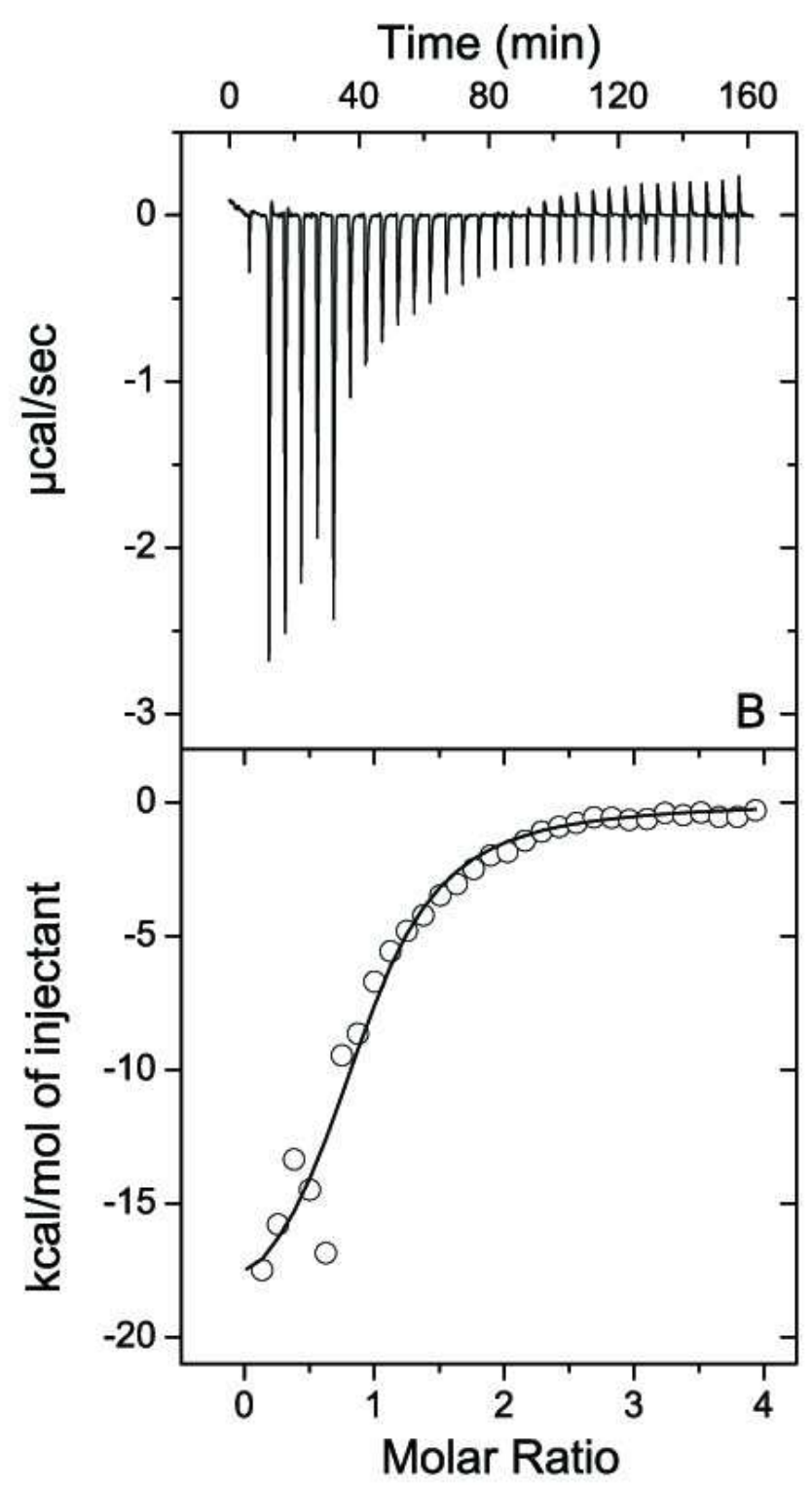

$210 \times 297 \mathrm{~mm}(72 \times 72 \mathrm{DPI})$ 


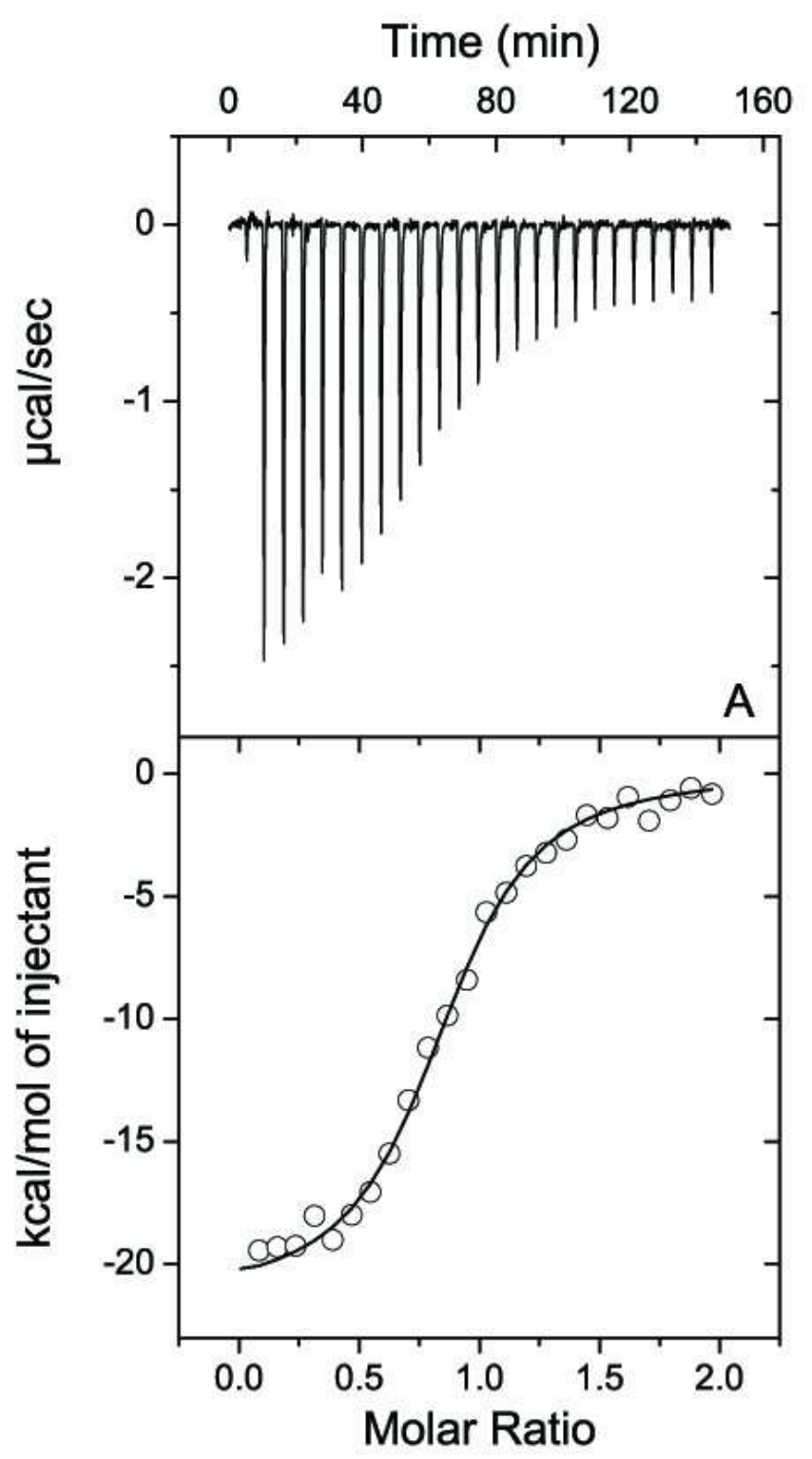

$210 \times 297 \mathrm{~mm}(72 \times 72 \mathrm{DPI})$ 